\title{
RGD-conjugated mesoporous silica-encapsulated gold nanorods enhance the sensitization of triple- negative breast cancer to megavoltage radiation therapy
}

\author{
This article was published in the following Dove Press journal: \\ International Journal of Nanomedicine \\ 27 October 2016 \\ Number of times this article has been viewed
}

\author{
Ning Zhao ${ }^{1,2, *}$ \\ Zhangru Yang $2,3, *$ \\ Bingxin $\mathrm{Li}^{2}$ \\ Jin Meng ${ }^{2}$ \\ Zeliang Shi ${ }^{2}$ \\ Ping $\mathrm{Li}^{4}$ \\ Shen $\mathrm{Fu}^{4}$ \\ 'Department of Radiation Oncology, \\ Fudan University Shanghai Cancer \\ Center, Shanghai, People's Republic \\ of China; ${ }^{2}$ Department of Radiation \\ Oncology, 6th People's Hospital \\ of Shanghai Jiao Tong University, \\ Shanghai, People's Republic of China; \\ ${ }^{3}$ Med-X Research Institute and School \\ of Biomedical Engineering, Shanghai \\ Jiao Tong University, Shanghai, People's \\ Republic of China; ${ }^{4}$ Department \\ of Radiation Oncology, Shanghai \\ Proton and Heavy lon Center, Fudan \\ University Shanghai Cancer Center, \\ Shanghai, People's Republic of China \\ *These authors contributed equally \\ to this work
}

\begin{abstract}
Multifunctional nanoprobes have great potential as effective radiosensitizers and drug carriers. RGD-modified gold nanorods could increase the uptake of nanoparticles via receptor-mediated endocytosis in integrin alphaV beta3-overexpressing breast cancer cells, which could enhance the effects of radiation on tumor cells, leading to further radiosensitization. The purpose of our study was to demonstrate that RGD-conjugated mesoporous silica-encapsulated gold nanorods significantly enhanced the sensitization of triple-negative breast cancer to megavoltage energy. The results indicated that RGD-conjugated mesoporous silica-encapsulated gold nanorod multifunctional nanoprobes could achieve radiosensitization in vitro and in vivo, which suggests the potential translation of this nanotechnology to clinical applications in tumor-targeting and selective therapy.
\end{abstract}

Keywords: gold nanorods, triple-negative breast cancer, Arg-Gly-Asp peptides, integrin alphaV beta3, megavoltage radiation therapy

\section{Introduction}

Nanotechnology is an evolving field that has been applied in the diagnosis and treatment of cancer. ${ }^{1,2}$ Among nanomaterials, gold nanoparticles (GNPs) are currently under intense investigation in cancer diagnostics, imaging, photothermal therapy, and radiotherapy because of their superior properties of low cytotoxicity, biocompatibility, and preferential accumulation in tumors (the "enhanced permeability and retention" effect). ${ }^{3-6}$ Numerous studies have shown that GNPs can be used as effective radiosensitizers by enhancing the efficacy of physical radiation (RT) on tumor cells..$^{7-9}$ In published studies, kilovolt radiosensitization has been attributed to increased photon absorption in high-Z materials compared with soft tissue. Photoelectric absorption is more prominent at kilovolt energies than at megavolt energies, at which the Compton effects are dominant. Monte Carlo modeling has predicted a higher physical dose enhancement with GNPs at kilovolt energies than at megavolt energies. Nevertheless, the inherently shallow penetration of kilovolt energies hampers the clinical translation of nanotechnology for cancer therapy. Currently, megavolt X-rays are essential for most radical radiotherapy regimes for the treatment of various tumors, and recent studies have demonstrated that GNP-mediated radiosensitization can be realized even with megavolt photons. ${ }^{10-12}$

Triple-negative breast cancer (TNBC), an aggressive subtype of breast cancer, is characterized by negative expression of estrogen, progesterone, and human epidermal 
growth factor receptor 2 , which renders it insensitive to both endocrine therapy and targeted therapy. ${ }^{13}$ TNBC accounts for $\sim 15 \%-20 \%$ of invasive breast cancers, presents at an advanced histological stage, and is associated with a poor prognosis and a distinct possibility of locoregional recurrence and distant metastasis. ${ }^{13-16}$ Given that TNBC presents with radiotherapy resistance, the development of a radiosensitizer is highly desirable. ${ }^{17}$ GNPs have been shown to enhance the sensitization of MDA-MB-231 TNBC cells to 6 MV X-rays with a sensitizer enhancement ratio (SER) of 1.29. ${ }^{18}$

Integrin alphaV beta3 $\left(\alpha_{\mathrm{v}} \beta_{3}\right)$, an extracellular matrix receptor, is involved in tumor invasion, metastasis, and angiogenesis. ${ }^{19}$ Arginine-glycine-aspartic acid (ArgGly-Asp, RGD) peptides are targeting ligands that specifically bind to integrin $\alpha_{\mathrm{v}} \beta_{3}{ }^{20}{ }^{20}$ Studies have shown that antagonists of the integrin $\alpha_{\mathrm{v}} \beta_{3}$ receptor enhance the RT response in multiple types of cancer. ${ }^{21-23}$ Thus, combining RGD peptides with nanotechnology could preferentially inhibit tumor tissues in a targeted manner without affecting normal tissues. We focused on the radiosensitizing effects of gold nanorods (GNRs) because they are small, easy to synthesize, and endowed with a high absorption cross-section. ${ }^{24,25}$ To improve the biocompatibility and stability of GNRs, we used mesoporous silica to encapsulate GNRs ( $\left.\mathrm{GNRs} @ \mathrm{mSiO}_{2}\right)$ and then modified the surface with polyethylene glycol (PEG) to prolong the retention time of the GNRs in the blood and to avoid instantaneous elimination from the body by reducing the uptake of GNRs by the reticuloendothelial system. Ultimately, we conjugated RGD peptides to the terminal PEG groups on GNRs@mSiO and cyclic RGDfC (c(RGDfC)) peptides were chosen based on the rigidity and variety of possible chemical modifications. Recently, studies have been published on the application of RGD-conjugated GNPs (RGD-GNPs) in radiotherapy, ${ }^{25,26}$ and our previous studies demonstrated that RGD-modified gold nanorods (RGD-GNRs) markedly enhanced the radiosensitization of melanoma cells by downregulating $\alpha_{\mathrm{v}} \beta_{3}$ expression in vitro. ${ }^{27,28}$ In this study, we selected the MDA-MB-231 TNBC cell line as the model system and investigated the radiosensitizing effects of RGD-conjugated mesoporous silica-encapsulated gold nanorods (pGNRs@mSiO $-\mathrm{RGD}$ ) multifunctional nanoprobes in response to megavoltage RT energy both in vitro and in vivo.

\section{Materials and methods \\ Materials}

Chloroauric acid $\left(\mathrm{HAuCl}_{4} \cdot 3 \mathrm{H}_{2} \mathrm{O}\right)$, cetyltrimethylammonium bromide (CTAB), sodium borohydride $\left(\mathrm{NaBH}_{4}\right)$, silver nitrate $\left(\mathrm{AgNO}_{3}\right)$, and ascorbic acid (AA) were purchased from
Sinopharm Chemical Reagent Co., Ltd (Shanghai, People's Republic of China). Tetraethoxysilane, (3-aminopropyl) triethoxysilane, anhydrous ethanol, and ammonia $\left(\mathrm{NH}_{3} \cdot \mathrm{H}_{2} \mathrm{O}\right)$ were obtained from Shanghai Chemical Reagents Co., Ltd. (Shanghai, People's Republic of China). MaleimidePEG3500-NHS was obtained from JenKem Technology USA (Allen, TX, USA), and c(RGDfC) was purchased from GL Biochem Co., Ltd. (Shanghai, People's Republic of China). Dulbecco's Modified Eagle's Medium (DMEM), fetal bovine serum, phosphate-buffered saline (PBS), penicillin-streptomycin solution, and trypsin-EDTA solution were purchased from Thermo Fisher Scientific (Waltham, MA, USA). The cell counting kit-8 assay was purchased from Beyotime Institute of Biotechnology (Shanghai, People's Republic of China). All the abovementioned chemicals were used without any further purification. Deionized water (Milli-Q grade; EMD Millipore, Billerica, MA, USA) with a resistivity of 18.2 $\mathrm{M} \Omega \mathrm{cm}$ was used in all the preparations.

\section{Synthesis of GNRs}

Bare rod-shaped GNRs were synthesized by the seedmediated growth method. ${ }^{29}$ First, $300 \mu \mathrm{L}$ of ice cold $0.01 \mathrm{M}$ $\mathrm{NaBH}_{4}$ was added to $5.0 \mathrm{~mL}$ of aqueous solution containing $0.1 \mathrm{M} \mathrm{CTAB}$ and $5 \mu \mathrm{L}$ of $10 \% \mathrm{HAuCl}_{4}$ under vigorous stirring. Then, the seed solution was incubated at $30^{\circ} \mathrm{C}$ for 2 hours. The growth solution consisted of $100 \mathrm{~mL}$ of $0.2 \mathrm{M}$ CTAB, $1 \mathrm{~mL}$ of $0.01 \mathrm{M} \mathrm{AgNO}_{3}, 5 \mathrm{~mL}$ of $0.01 \mathrm{M} \mathrm{HAuCl}_{4}$, $800 \mu \mathrm{L}$ of $0.01 \mathrm{M} \mathrm{AA}$, and $2 \mathrm{~mL}$ of $\mathrm{H}_{2} \mathrm{SO}_{4}$. After gently mixing the growth solution, $250 \mu \mathrm{L}$ of the seed solution was added, and the solution was incubated at $30^{\circ} \mathrm{C}$ for 24 hours to obtain the GNRs. The product was washed with deionized water several times, and the supernatant, which contained excess CTAB, was removed. Then, the solid (containing the GNRs) was redispersed in $20 \mathrm{~mL}$ of deionized water.

\section{Synthesis of GNRs@mSiO}

The mesoporous silica coating was achieved by the modified Stöber method. ${ }^{30}$ A tetraethoxysilane/ethanol solution ( $1 \mathrm{~mL}$ ) was added to the diluted GNR system, which was adjusted to pH 10 with $0.1 \mathrm{M} \mathrm{NaOH}$. The resulting mixture was gently stirred for 24 hours. The synthesized product was washed several times with deionized water and ethanol, and the CTAB template was removed in an ethanol solution of $\mathrm{NH}_{4} \mathrm{NO}_{3}$ through ion exchange. Then, the obtained purified mesoporous silica-modified gold nanorods $\left(\mathrm{GNRs} @ \mathrm{mSiO}_{2}\right)$ samples were redispersed in ethanol for further characterization and functionalization. Subsequently, the abovementioned solution was mixed with aqueous ammonia and $100 \mu \mathrm{L}$ of 
(3-aminopropyl) triethoxysilane. After a 24-hour reaction, the resultant was collected by centrifugation and washed repeatedly with ethanol. The obtained GNRs@mSiO $-\mathrm{NH}_{2}$ samples were then redispersed in ethanol for further use.

\section{Construction of pGNRs@mSiO $-R G D$}

Briefly, the abovementioned GNRs@mSiO $-\mathrm{NH}_{2}$ solution was mixed with NHS-PEG3500-MAL and allowed to shake for 3 hours at room temperature. The terminal NHS group of the bifunctional PEG derivative was specifically reacted with the primary amino groups on the surface of the GNRs@ $\mathrm{mSiO}_{2}$. The resulting product was washed with distilled water to remove unreacted chemicals by centrifugation. Subsequently, c(RGDfC) was added to the abovementioned purified solution, and the thiol groups of $\mathrm{c}(\mathrm{RGDfC})$ were reacted with the terminal MAL group of the bifunctional PEG derivative for 4 hours at room temperature. The products were washed with distilled water to remove unreacted chemicals by centrifugation. The obtained purified pGNRs@mSiO - RGD samples were redispersed in PBS for further application and characterization. The conjugated nanoparticles were stored at $4^{\circ} \mathrm{C}$ in deionized water, and no aggregation was observed over a period of 24 hours.

\section{Characterization of GNRs}

The ultraviolet-visible (UV-Vis) absorbance spectra of GNRs and GNRs@mSiO, were measured using a UV-Vis spectrophotometer (Cary-100; Agilent Technologies, Santa Clara, CA, USA) in the wavelength region of 400-1,000 nm. $\mathrm{c}$ (RGDfC) and pGNRs@ $\mathrm{mSiO}_{2}$-RGD were also analyzed in the wavelength range of 200-600 $\mathrm{nm}$. The surface charge and the hydrodynamic diameters of the GNPs were measured using a Malvern Zetasizer Nano-ZS 90 (Malvern Instruments, Malvern, UK) in deionized water. GNRs and GNRs@ $\mathrm{mSiO}_{2}$ samples were analyzed using transmission electron microscope (TEM; JEM-2010HT; JEOL, Tokyo, Japan) at $200 \mathrm{kV}$.

\section{Cell culture}

MDA-MB-231 cells (human TNBC epithelial cell line) and MCF-10A normal human mammary epithelial cells were obtained from American Type Culture Collection (ATCC, Manassas, VA, USA) and cultured in DMEM supplemented with $10 \%$ fetal bovine serum, $10,000 \mathrm{U} / \mathrm{mL}$ penicillin, and $10,000 \mu \mathrm{g} / \mathrm{mL}$ streptomycin. Besides, in the case of MCF-10A, the DMEM was supplemented also with insulin $(10 \mu \mathrm{g} / \mathrm{mL})$, epidermal growth factor $(20 \mathrm{ng} / \mathrm{mL})$, and hydrocortisone $(0.5 \mu \mathrm{g} / \mathrm{mL})$ according to the procedure reported.
Cells were incubated at $37^{\circ} \mathrm{C}$ in a humidified atmosphere containing $5 \% \mathrm{CO}_{2}$. All the experiments were conducted with cells in the logarithmic growth stage.

\section{Cytotoxicity}

MCF-10A normal cells were seeded in 96-well plates at a density of $5 \times 10^{3}$ cells per well and incubated overnight. Then, the media was replaced with $100 \mu \mathrm{L}$ of fresh media containing varying concentrations of pGNRs@ $\mathrm{mSiO}_{2}$ or pGNRs@ $\mathrm{mSiO}_{2}$-RGD nanoprobes. Subsequently, the cells were rinsed with PBS and incubated for another 24 hours. Finally, the cell counting kit- 8 assay was used to determine the cell viability according to the manufacturer's instructions.

\section{Cellular binding and internalization}

A $5 \mathrm{~mL}$ MDA-MB-231 cell suspension containing $1 \times 10^{6}$ cells was seeded and grown in $6 \mathrm{~cm}$ Petri dishes until they reached 70\%-80\% confluence. Then, pGNRs@mSiO and pGNRs@ $\mathrm{mSiO}_{2}-\mathrm{RGD}$ were added into the medium, respectively, for a final concentration of $50 \mu \mathrm{g} / \mathrm{mL}$. To verify that the increased cellular uptake was caused by RGD-mediated targeting effect, we used free RGD to block the surface receptor first and then added pGNRs@mSiO $-\mathrm{RGD}$ nanoprobes to check if its internalization was suppressed as well. After incubation at different intervals $(0.5,1,2,4,8,12,24,48$, and 72 hours), the cells were collected and then resuspended into PBS for a final volume of $5 \mathrm{~mL}$. Cells were counted with a hemocytometer and then dissolved in aqua regia. The amount of gold was measured by inductively coupled plasma atomic emission spectroscopy. The quantitative measurement of GNPs cell uptake was done using the following formula: mass of GNPs per cell $=$ mass of GNPs in the lysis/number of cells.

\section{Clonogenic assessment}

A $5 \mathrm{~mL}$ MDA-MB-231 cell suspension was seeded in $60 \times 15 \mathrm{~mm}$ culture dishes and allowed to attach overnight. A total of $1 \mathrm{mg} / \mathrm{mL}, 250 \mu \mathrm{L}$ of pGNRs@mSiO ${ }_{2}$ or pGNRs@ $\mathrm{mSiO}_{2}-\mathrm{RGD}$ nanoprobes were added to the cells, after incubating for 24 hours, the noninternalized nanoparticles were removed from the medium, and the cells were washed with PBS. Then, the cells were irradiated with $6 \mathrm{MV}$ X-rays, corresponding to total doses of $0-10$ Gy in a single fraction. Cells were then incubated for 14 days to allow for colony formation. Subsequently, the cells were washed, fixed with methanol, and stained with $0.4 \%$ crystal violet. Colonies were counted with a cutoff of 50 cells. Plating efficiency, survival fraction $(\mathrm{SF})$, and radiosensitization parameters, including average lethal dose $\left(D_{0}\right)$, quasi-threshold dose $\left(D_{\mathrm{q}}\right)$, and 
$\mathrm{SER}_{D 0 / D q / \mathrm{SF} 2}$, were calculated. The dose-survival curve was fitted using a single-hit multitarget statistical model. Three parallel samples were analyzed at each RT dosage.

\section{Flow cytometry analysis of cell cycle, apoptosis, and reactive oxygen species levels}

MDA-MB-231 cells were exposed to $50 \mu \mathrm{g} / \mathrm{mL}$ of pGNRs@ $\mathrm{mSiO}_{2}$ or pGNRs@mSiO $-\mathrm{RGD}$ nanoprobes for 24 hours. Then, the cells were washed with PBS and irradiated with $6 \mathrm{MV}$ X-rays at a dose of $6 \mathrm{~Gy}$. For the cell cycle assay, the cells were collected 24 hours after RT, fixed in $70 \%$ ethanol at $4^{\circ} \mathrm{C}$ for 24 hours, resuspended in PBS, stained with $50 \mu \mathrm{g} / \mathrm{mL}$ propidium iodide and $10 \mu \mathrm{g} / \mathrm{mL}$ RNase, and incubated at $37^{\circ} \mathrm{C}$ for 30 minutes. For the apoptosis assay, the cells were collected 24 hours after RT and incubated for 15 minutes with $100 \mu \mathrm{L}$ of $1 \times$ buffer solution, $5 \mu \mathrm{L}$ of FITC-annexin- $\mathrm{V}$, and $5 \mu \mathrm{L}$ of $\mathrm{PI}$ at $25^{\circ} \mathrm{C}$. The analysis was performed according to the Alexa Fluor ${ }^{\circledR} 488$ annexin-V/ Dead Cell Kit (Thermo Fisher Scientific) instructions. For the reactive oxygen species (ROS) level assay, the cells were collected 24 hours after RT and treated with DCFH-DA $(10 \mu \mathrm{mol} / \mathrm{L})$ at $37^{\circ} \mathrm{C}$ in the dark for 20 minutes. ROS levels were quantified using a Reactive Oxygen Species Assay Kit (KeyGen Biotech. Co., Ltd, Nanjing, People's Republic of China). The samples were analyzed using a FACSCalibur flow cytometer (BD, Franklin Lakes, NJ, USA).

\section{Western blotting}

MDA-MB-231 cells were treated under various conditions: no treatment (control), pGNRs@ $\mathrm{mSiO}_{2}-\mathrm{RGD}$ $(50 \mu \mathrm{g} / \mathrm{mL})$ alone, RT (6 Gy) alone, or pGNRs@ $\mathrm{mSiO}_{2}-\mathrm{RGD}$ $(50 \mu \mathrm{g} / \mathrm{mL})+\mathrm{RT}$ (6 Gy). Cells in each group were washed with PBS and then treated with RIPA lysis buffer (Beyotime Institute of Biotechnology) supplemented with protease inhibitor cocktail. The total protein was extracted, and the protein concentration was assessed using a bicinchoninic acid protein assay reagent (KeyGen Biotech, Co., Ltd.) with bovine serum albumin as the standard. Equal amounts of protein per well were loaded in $10 \%$ sodium dodecyl sulfate-polyacrylamide gel electrophoresis denaturing gels (Beyotime Institute of Biotechnology) and then electrotransferred to polyvinylidene fluoride membranes (EMD Millipore). The membranes were blocked in $0.1 \%$ Tween-20 (TBST) containing 5\% skim milk and then incubated with a primary antibody against $\alpha_{v} \beta_{3}(1: 1,000$ dilution $)$ at $4{ }^{\circ} \mathrm{C}$ overnight. Subsequently, the membranes were washed with TBST for 15 minutes, incubated with secondary antibody (1:2,000 dilution) for 4 hours at room temperature, and washed with TBST for 15 minutes. Enhanced chemiluminescence detection reagent (Beyotime Institute of Biotechnology) was used to visualize the protein of interest.

\section{Orthotopic transplantation models of human TNBC}

Female nude mice, aged 6-8 weeks and weighing $20 \pm 2$ g, were purchased from Shanghai Laboratory Animal Co., Ltd (Shanghai, People's Republic of China) and maintained under standard housing conditions in Department of Experimental Animals, Six people's Hospital of Shanghai Jiao Tong University (Shanghai, People's Republic of China).

All animal experiments were carried out in accordance with guidelines evaluated and approved by the ethics committee of Shanghai Jiao Tong University. The orthotopic models were established by injecting $2 \times 10^{6}$ MDA-MB-231 cells into the abdominal fat pad of the mice. After the tumors had reached $\sim 6-8 \mathrm{~mm}$ in the longest diameter, the experiments were initiated.

\section{Biodistribution}

The nude mice harboring TNBC were randomly divided into two groups (six mice per group) and then received a tail vein injection of pGNRs@mSiO ${ }_{2}$ and pGNRs@mSiO $-\mathrm{mGD}$ ( $1 \mathrm{mg} \mathrm{Au}$ in $200 \mu \mathrm{L}$ of PBS, equivalent to $\sim 50 \mu \mathrm{g}$ of Au per gram of body weight), respectively. All the mice were sacrificed 24 hours after injection, and various tissues, including tumor specimens, were extracted. The organs were lysed in aqua regia overnight. The gold content was quantified by inductively coupled plasma mass spectrometry.

\section{In vivo assessment of tumor regression}

The nude mice bearing TNBC were randomized into five treatment groups (six mice per group): no treatment (control group), RGD (negative control group), RT alone (Group III), pGNRs@mSiO ${ }_{2}$ plus RT (Group IV), and pGNRs@mSiO ${ }_{2}$ RGD plus RT (Group V). In Groups IV and V, the mice were injected with pGNRs@ $@ \mathrm{mSiO}_{2}$ or pGNRs@ $\mathrm{mSiO}_{2}-\mathrm{RGD}$ ( $1 \mathrm{mg} \mathrm{Au}$ in $200 \mu \mathrm{L}$ of PBS) through the tail vein 24 hours prior to local irradiation with a single dose of $10 \mathrm{~Gy}$. The negative control group was treated with $1 \mathrm{mg}$ of RGD in $200 \mu \mathrm{L}$ of PBS 24 hours prior to RT. Subsequently, the tumor growth was monitored by vernier caliper measurements every 2 days. The tumor volume was calculated using the formula: volume $=\left(\right.$ length $/$ width $\left.^{2}\right) / 2$, where the length and width were the two largest perpendicular diameters. One month after injection, all the mice were euthanized and the tumors were collected. The degree of radiosensitization was assessed by comparing the tumor volumes between the groups. Moreover, 
to characterize the distribution of pGNRs@ $\mathrm{mSiO}_{2}-\mathrm{RGD}$ in the tumor tissues after systemic administration, the tumor tissues collected from mice treated with pGNRs@ $\mathrm{mSiO}_{2}$ RGD were analyzed using TEM. The tumor tissues were cut into $1 \mathrm{~mm}^{3}$ sections, fixed with $2.5 \%$ glutaraldehyde for 2 hours, washed with PBS, and dehydrated in serial concentrations of ethanol. Subsequently, the tissues were soaked in propylene oxide and Epon mixture and then embedded at $60^{\circ} \mathrm{C}$ for 48 hours. After staining, the sections were observed using a TEM (PHILIP CM-120, $80 \mathrm{kV}$ ).

\section{Statistical analysis}

A two-tailed unpaired Student's $t$-test was used for the statistical analysis, with $P<0.05$ considered statistically significant. All the experiments were conducted in triplicate. The results are presented as the mean \pm SD unless otherwise indicated. SPSS 11.0 software was used for all the statistical analyses.

\section{Results}

\section{Synthesis and characterization of pGNRs@mSiO - RGD nanoprobes}

Figure 1A shows a TEM image of the GNRs. The average length and width of the GNRs were $57.70 \mathrm{~nm}$ and $14.44 \mathrm{~nm}$, respectively. Figure 1B shows a TEM image of the GNRs@ $\mathrm{mSiO}_{2}$ core-shell nanoprobes; the halos that formed around the nanorods represent the silica layer, the thickness of which was $\sim 18.34 \mathrm{~nm}$. As shown in Figure 2, the GNRs had two absorption peaks. The longitudinal surface plasmon resonance peak of the GNRs was at $834 \mathrm{~nm}$, and the GNRs@ $\mathrm{mSiO}_{2}$ exhibited a red-shift in the absorption peak of $\sim 40 \mathrm{~nm}$ compared with the GNRs, which was attributed to the increased refractive index caused by the silica layer on the surface of the GNRs. ${ }^{31}$ The transverse surface plasmon resonance peaks remained nearly unchanged $(502 \mathrm{~nm})$. We also assessed the zeta potential (surface charge) of the nanorods in various synthetic phases. The zeta potential was used to alternatively conceptualize the conjugation process based
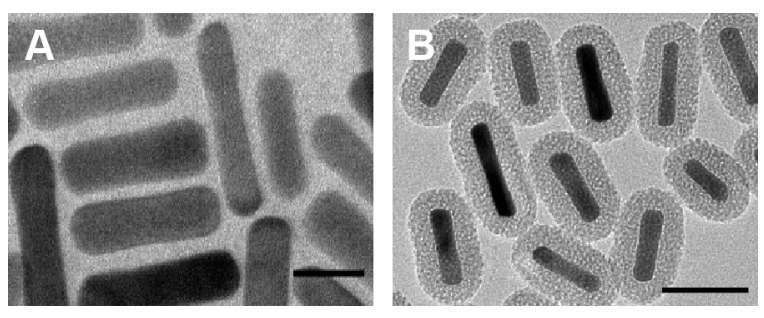

Figure I TEM images of (A) GNRs (scale bar $=20 \mathrm{~nm}$ ) and (B) GNRs@mSiO (scale bar $=50 \mathrm{~nm}$ ).

Note: GNRs@mSiO

Abbreviations: TEM, transmission electron microscope; GNRs, gold nanorods.

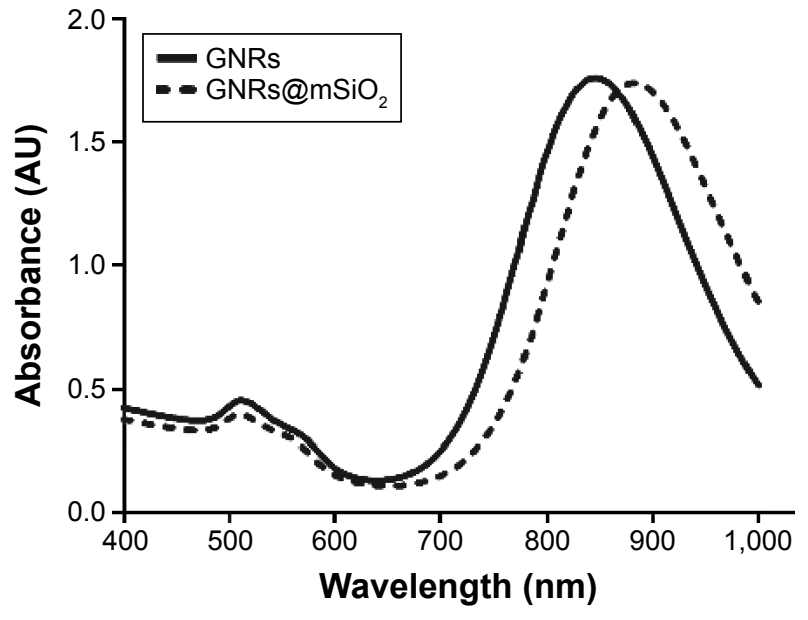

Figure 2 UV-Vis extinction spectra of the synthesized GNRs and GNRs@mSiO (400-I,000 nm).

Note: GNRs@mSiO , mesoporous silica-encapsulated gold nanorods.

Abbreviations: UV-Vis, ultraviolet-visible; GNRs, gold nanorods.

on the net charge at the surface of the nanorods. Figure 3 shows that both $\mathrm{c}(\mathrm{RGDfC})$ and pGNRs@ $\mathrm{mSiO}_{2}-\mathrm{RGD}$ had an absorbance peak at $\sim 204 \mathrm{~nm}$, as measured by UV-Vis spectroscopy, which indicates that $\mathrm{c}(\mathrm{RGDfC})$ is located on the pGNRs@mSiO . The zeta potential of the bare GNRs was $26.6 \pm 10.9 \mathrm{mV}$, which indicates a strong positive charge due to the surfactant CTAB. The zeta potential of GNRs@ $\mathrm{mSiO}_{2}$ was $-25.4 \pm 6.33 \mathrm{mV}$ due to the numerous $\mathrm{OH}$ groups on the surface of the GNRs@mSiO . The strong negative charge on the GNRs@ $\mathrm{mSiO}_{2}$ was neutralized by many $\mathrm{NH}_{2}$ groups on the surface of the GNRs@ $\mathrm{mSiO}_{2}-\mathrm{NH}_{2}$, and the zeta potential of the GNRs@mSiO $-\mathrm{NH}_{2}$ was $35.1 \pm 7.01 \mathrm{mV}$ (Figure $\mathrm{S} 1$ ). We also measured the hydrodynamic diameters of the pGNRs@ $\mathrm{mSiO}_{2}-\mathrm{RGD}$ nanoprobes at different periods

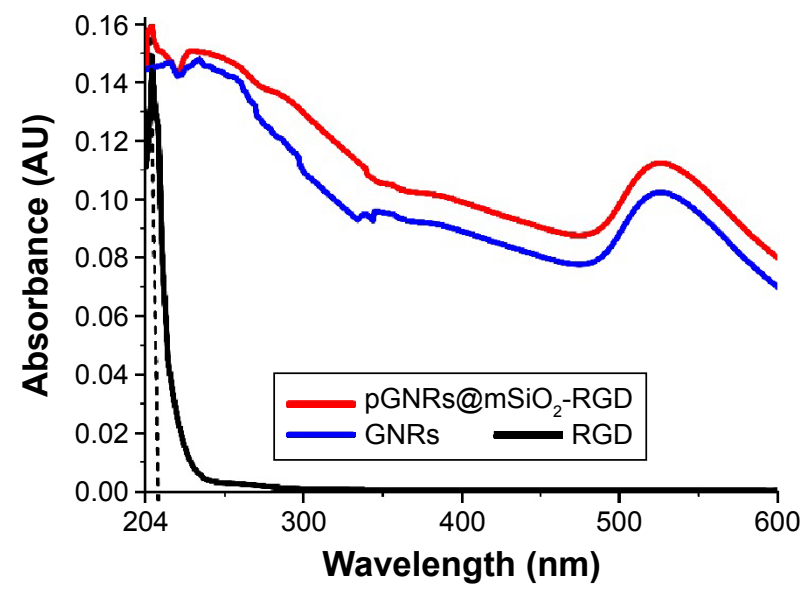

Figure 3 UV-Vis extinction spectra of c(RGD), pGNRs@mSiO ${ }_{2}-R G D$, and GNRs $(200-600 \mathrm{~nm})$.

Notes: GNRs@mSiO , mesoporous silica-encapsulated gold nanorods; RGD, arginine-glycine-aspartic acid (Arg-Gly-Asp, RGD) peptides; pGNRs@mSiO 2 -RGD, RGD-conjugated mesoporous silica-encapsulated gold nanorods.

Abbreviations: c(RGD), cyclic RGD; GNRs, gold nanorods; UV-Vis, ultravioletvisible. 
of time ( 0.5 hour, 24 hours, and 1 month), and the findings indicated that the hydrodynamic diameters of the pGNRs@, $\mathrm{mSiO}_{2}-\mathrm{RGD}$ nanoprobes remained invariable and no aggregation was observed, which suggests that the pGNRs@ $\mathrm{mSiO}_{2}-\mathrm{RGD}$ nanoprobes have good stability (Figure S2).

\section{Cytotoxicity assessment}

It is essential to assess the cytotoxicity of the GNPs to evaluate their clinical potential. The viability of MCF-10A normal cells exposed to pGNRs@ $\mathrm{mSiO}_{2}$ or pGNRs@mSiO RGD nanoprobes was determined by the cell counting kit- 8 assay. The viability of the cells in the control group was assumed to be $100 \%$. The cell viability remained $>90 \%$ after incubation with various concentrations of either gold nanoprobe, which indicated that our gold nanoprobes had low cytotoxicity (Figure 4).

\section{Cellular binding and uptake}

Figure 5 shows the cellular uptake efficiency of the nanorods, the uptake of the pGNRs@mSiO${ }_{2}$-RGD was significantly higher than that of the pGNRs@mSiO . Moreover, the cellular uptake of the pGNRs@ $\mathrm{mSiO}_{2}$-RGD occurred in a time-dependent manner, with the concentration peaking at 24 hours: the uptake values of pGNRs@ $\mathrm{mSiO}_{2}-\mathrm{RGD}$ and pGNRs@ $\mathrm{mSiO}_{2}$ were $125.89 \pm 4.47$ pg and 27.17 \pm 4.39 pg, respectively $(P<0.05)$, and the cellular internalization of pGNRs@ $\mathrm{mSiO}_{2}-\mathrm{RGD}$ reduced to $30.76 \pm 7.31 \mathrm{pg}$ when the surface receptor $\alpha_{v} \beta_{3}$ was blocked with free RGD first. Besides, MDA-MB-231 cells absorbed pGNRs@ $\mathrm{mSiO}_{2}-\mathrm{RGD}$

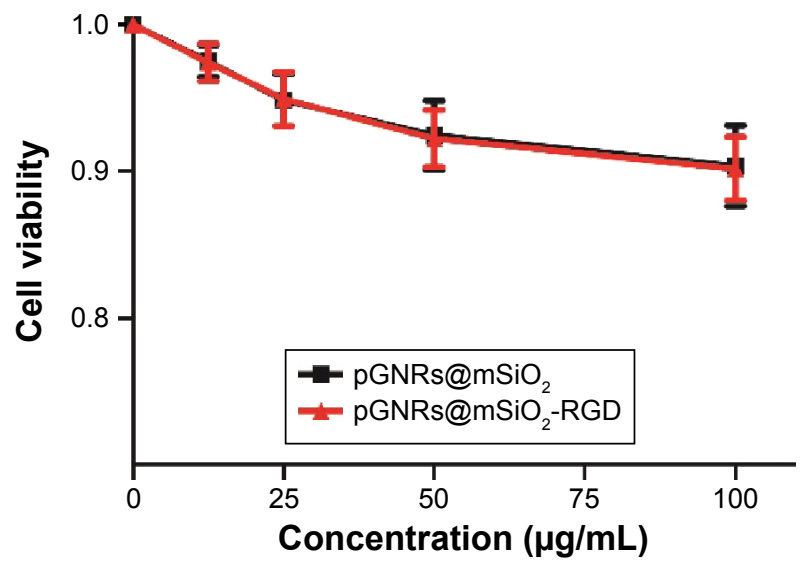

Figure $4 \mathrm{MCF}-10 \mathrm{~A}$ normal cells were incubated with different concentrations $(0-100 \mu \mathrm{g} / \mathrm{mL})$ of $\mathrm{pGNRs} @ \mathrm{mSiO}_{2}$ or $\mathrm{pGNRs@mSiO}{ }_{2}-\mathrm{RGD}$ nanoprobes for 24 hours at $37^{\circ} \mathrm{C}$.

Notes: The cell viability was examined by CCK-8 assay. pGNRs@mSiO, mesoporous silica-encapsulated gold nanorods; pGNRs@mSiO $-\mathrm{RGD}, \mathrm{RGD}-$ conjugated mesoporous silica-encapsulated gold nanorods; RGD, arginine-glycineaspartic acid (Arg-Gly-Asp) peptides.

Abbreviation: CCK-8 assay, cell counting kit-8 assay.

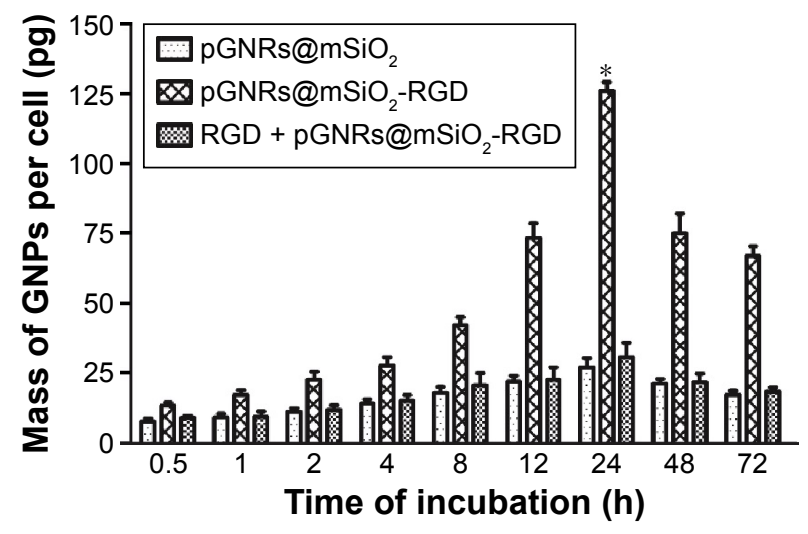

Figure 5 Quantitative analysis of the cellular internalization of gold nanoprobes. Notes: MDA-MB-23। cells were treated with (I) $50 \mu \mathrm{g} / \mathrm{mL}$ pGNRs@mSiO ; (II) $50 \mu \mathrm{g} / \mathrm{mL}$ pGNRs@mSiO - RGD; (III) free RGD combined with $50 \mu \mathrm{g} / \mathrm{mL}$ pGNRs@ $\mathrm{mSiO}_{2}-\mathrm{RGD}$, respectively, for different times (0.5-72 hours). Compared with the pGNRs@mSiO2 group, *P<0.05. pGNRs@mSiO , mesoporous silica-encapsulated gold nanorods; PGNRs@mSiO $2-R G D$, RGD-conjugated mesoporous silicaencapsulated gold nanorods.

Abbreviations: RGD, arginine-glycine-aspartic acid (Arg-Gly-Asp) peptides; GNPs, gold nanoparticles; $h$, hours.

more than pGNRs@ $\mathrm{mSiO}_{2}$ at each time interval $(P<0.05)$, and the uptake of pGNRs@mSiO 2 -RGD was markedly impressed when $\alpha_{v} \beta_{3}$ receptor was blocked first. This result suggested that the increased cellular uptake was caused by RGD-mediated targeting effect and pGNRs@mSiO 2 -RGD could act as a transmembrane carrier to increase the cellular internalization of the nanoparticles.

\section{Radiosensitization of MDA-MB-23 I cells by pGNRs@mSiO - -RGD nanoprobes}

The clonogenic formation assay was used to determine the enhancement of the radiosensitization by the pGNRs@ $\mathrm{mSiO}_{2}-\mathrm{RGD}$. The survival curves of the control, pGNRs@ $\mathrm{mSiO}_{2}$-treated, and pGNRs@ $\mathrm{mSiO}_{2}$-RGD-treated MDAMB-231 cells combined with megavoltage RT are shown in Figure 6. Table 1 lists the RT biology parameters of each group, which were calculated using the single-hit multitarget model. Both types of gold nanoprobes evoked radiosensitization, but the radiosensitizing effect of the pGNRs@ $\mathrm{mSiO}_{2}$ RGD nanoprobes was significantly greater than that of the pGNRs@mSiO ${ }_{2}$.

\section{Apoptosis analysis by flow cytometry}

Figures S3A-F and 7 show the percentages of cells undergoing apoptosis after various treatments. There were increased percentages of cells undergoing apoptosis in the groups treated with pGNRs@mSiO or pGNRs@mSiO $-\mathrm{RGD}$ with or without $6 \mathrm{MV} \mathrm{X}$-rays compared with the control group (7.34\% $\pm 0.18 \% ; P<0.001)$. More importantly, compared with pGNRs@ $\mathrm{mSiO}_{2}+\mathrm{RT}(31.65 \% \pm 1.85 \%)$ and RT alone 


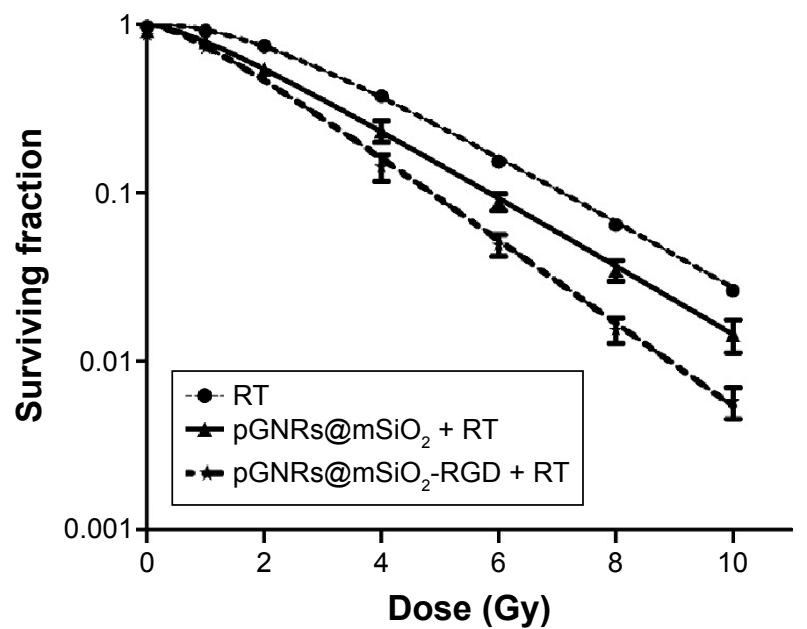

Figure 6 Survival fraction of MDA-MB-23I cells after incubation with pGNRs@ $\mathrm{mSiO}_{2}(50 \mu \mathrm{g} / \mathrm{mL})$ or pGNRs@mSiO - RGD $(50 \mu \mathrm{g} / \mathrm{mL})$ for 24 hours prior to laddered radiation doses (0, I, 2, 4, 6, 8, or I0 Gy) of 6 MV X-rays.

Notes: pGNRs@mSiO, mesoporous silica-encapsulated gold nanorods; pGNRs@ $\mathrm{mSiO}_{2}-\mathrm{RGD}, \mathrm{RGD}$-conjugated mesoporous silica-encapsulated gold nanorods; RGD, arginine-glycine-aspartic acid (Arg-Gly-Asp) peptides.

Abbreviations: RT, radiation; SER, sensitizer enhancement ratio.

(25.24\% $\pm 2.67 \%)$, pGNRs@mSiO 2 -RGD + RT significantly increased the apoptosis rate $(40.97 \% \pm 2.80 \% ; P<0.01)$, which may offer a potential mechanism for the radiosensitization effect of pGNRs@mSiO - -RGD nanoprobes.

\section{Cell cycle analysis by flow cytometry}

Radiosensitizers are known to cause cell accumulation in the radiosensitive $\mathrm{G}_{2} / \mathrm{M}$ phase of the cell cycle. As shown in Figures S4A-F and 8, there were more MDA-MB-231 cells in $\mathrm{G}_{2} / \mathrm{M}$ after treatment with pGNRs@ $\mathrm{mSiO}_{2}$ or pGNRs@ $\mathrm{mSiO}_{2}$-RGD with or without 6 MV X-rays than after the control treatment $(13.23 \% \pm 1.96 \% ; P<0.05)$. Moreover, pGNRs@ $\mathrm{mSiO}_{2}$-RGD + RT further increased cell cycle arrest at $\mathrm{G}_{2} / \mathrm{M}(47.03 \% \pm 1.72 \%)$ compared with pGNRs@ $\mathrm{mSiO}_{2}+\mathrm{RT}(35.53 \% \pm 1.62 \%)$ and RT alone $(29.50 \% \pm 2.55 \%)(P<0.01)$; these data may help elucidate

Table I Radiation biology parameters of each group, which were calculated using the single-hit multi-target model

\begin{tabular}{|c|c|c|c|c|c|c|}
\hline Groups & $D_{0}(G y)$ & $D_{q}(G y)$ & $\mathbf{S F}_{2}$ & $\mathbf{S E R}_{\mathrm{D} 0}$ & $\mathbf{S E R}_{\mathrm{Dq}}$ & $\mathbf{S E R}_{\mathrm{SF} 2}$ \\
\hline RT & 2.20 & 2.09 & 0.74 & & & \\
\hline $\begin{array}{l}\text { pGNRs@mSiO }{ }_{2}+ \\
\text { RT }\end{array}$ & 2.14 & 0.96 & 0.54 & 1.03 & 2.19 & 1.37 \\
\hline $\begin{array}{l}\text { PGNRs@mSiO }{ }_{2}^{-} \\
\text {RGD + RT }\end{array}$ & 1.76 & 0.84 & 0.49 & 1.25 & 2.50 & 1.52 \\
\hline
\end{tabular}

Notes: pGNRs@mSiO 2 -RGD, RGD-conjugated mesoporous silica-encapsulated gold nanorods; pGNRs@mSiO ${ }_{2}$, mesoporous silica-encapsulated gold nanorods; RGD, arginine-glycine-aspartic acid (Arg-Gly-Asp) peptides; $D_{0}$, average lethal dose; $D_{q}$, quasi-threshold dose; $\mathrm{SF}_{2}$, survival fraction at radiation dose of $2 \mathrm{~Gy}$. Abbreviations: RT, radiation; SER, sensitizer enhancement ratio.

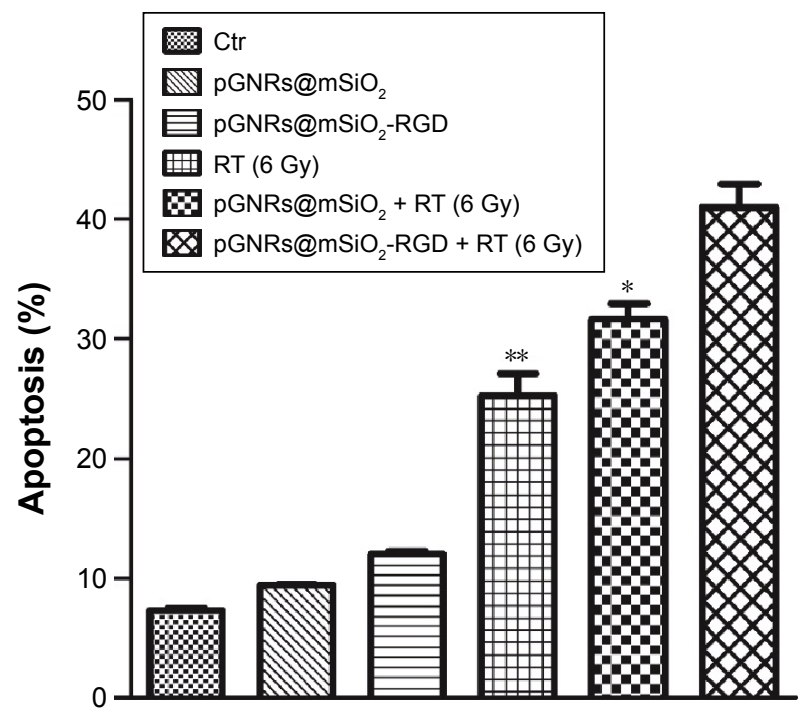

Figure 7 Flow cytometry analysis of MDA-MB-23I cell apoptosis.

Notes: Data were quantified and the results are presented as the mean $\pm S D(n=3$ experiments). Compared with the pGNRs@mSiO $2-R G D+R T$ group, $* * P<0.01$, $* P<0.05$. pGNRs@mSiO, mesoporous silica-encapsulated gold nanorods; pGNRs@ $\mathrm{mSiO}_{2}-\mathrm{RGD}, \mathrm{RGD}$-conjugated mesoporous silica-encapsulated gold nanorods; RGD, arginine-glycine-aspartic acid (Arg-Gly-Asp) peptides.

Abbreviations: Ctr, control; RT, radiation; SD, standard deviation.

the mechanism underlying the dose enhancement effect of pGNRs@mSiO 2 -RGD nanoprobes.

\section{Induction of intracellular ROS}

Measuring intracellular ROS levels is important for evaluating oxidative stress and the potential cytotoxicity of nanoparticles, which lead to oxidative damage to biomolecules and

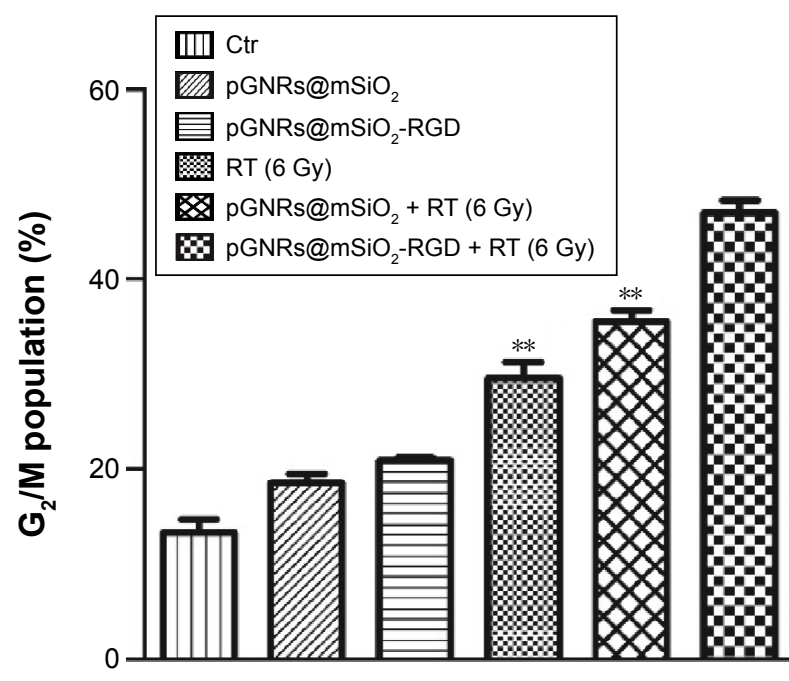

Figure 8 Flow cytometry analysis of $G_{2} / M$ cell cycle arrest in MDA-MB-23 I cells. Notes: Data were quantified and the results are presented as the mean $\pm S D(n=3$ experiments). Compared with the pGNRs@ $\mathrm{mSiO}_{2}-\mathrm{RGD}+\mathrm{RT}$ group, $* * \mathrm{p}<0.01$. pGNRs@mSiO ${ }_{2}$, mesoporous silica-encapsulated gold nanorods; pGNRs@ $\mathrm{mSiO}_{2}-\mathrm{RGD}, \mathrm{RGD}$-conjugated mesoporous silica-encapsulated gold nanorods; RGD, arginine-glycine-aspartic acid (Arg-Gly-Asp) peptides.

Abbreviations: Ctr, control; RT, radiation; SD, standard deviation. 


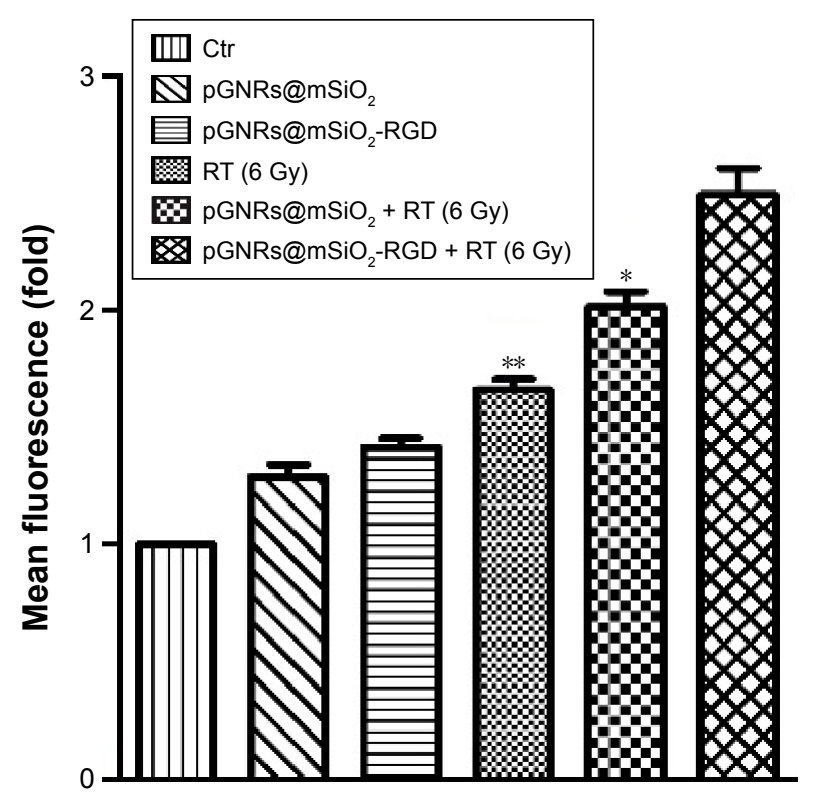

Figure 9 The ROS levels in MDA-MB-23I cells treated with pGNRs@mSiO, or pGNRs@mSiO - -RGD nanoprobes with or without $6 \mathrm{MV}$ X-rays (6 Gy) as determined by flow cytometry.

Notes: The fluorescence intensity indicates the ROS levels. The data were quantified, and the results are presented as the mean $\pm S D(n=3$ experiments). Compared with the $p G N R s @ m_{2} S_{2}-R G D+R T$ group, $* * P<0.01, * P<0.05$.

Abbreviations: pGNRs@mSiO $-\mathrm{RGD}$, RGD-conjugated mesoporous silicaencapsulated gold nanorods; ROS, reactive oxygen species; RGD, arginine-glycineaspartic acid (Arg-Gly-Asp) peptides; MV, megavoltage; Ctr, control; RT, radiation; $\mathrm{SD}$, standard deviation.

cell death. To examine the role of ROS in cell apoptosis, we measured cellular ROS levels by the DHE fluorescence method. Compared with the negative control group, the ROS levels in the pGNRs@mSiO 2 -RGD+RT group significantly increased by $2.50 \pm 0.16$-fold and were higher than those in the pGNRs@ $\mathrm{mSiO}_{2}+\mathrm{RT}(2.02 \pm 0.09$-fold) and RT (1.66 $\pm 0.06-$ fold) alone groups $(P<0.01)$ (Figure 9). This result demonstrated that pGNRs@mSiO - RGD nanoprobes may enhance the radiosensitivity by increasing cellular ROS levels.

\section{Integrin $\alpha_{v} \beta_{3}$ expression level}

A Western blot assay was used to investigate the expression of integrin $\alpha_{\mathrm{v}} \beta_{3}$. Figure 10 shows that the pGNRs@ $\mathrm{mSiO}_{2}$-RGD markedly downregulated $\alpha_{\mathrm{v}} \beta_{3}$ expression and that irradiation enhanced the expression of $\alpha_{\mathrm{v}} \beta_{3}$ compared with the control treatment $(P<0.05)$. MDA-MB-231 cells incubated with pGNRs@ $\mathrm{mSiO}_{2}$-RGD nanoprobes 24 hours prior to RT expressed lower integrin $\alpha_{\mathrm{v}} \beta_{3}$ levels than those treated with RT alone $(P<0.05)$. The $\beta$-actin bands were of equal intensity, indicating that the protein concentration was equal in all the loaded samples.

\section{Biodistribution}

Mouse models of TNBC were established (Figure S5). The distribution of pGNRs@ $\mathrm{mSiO}_{2}$ and pGNRs@mSiO $-\mathrm{mGD}$

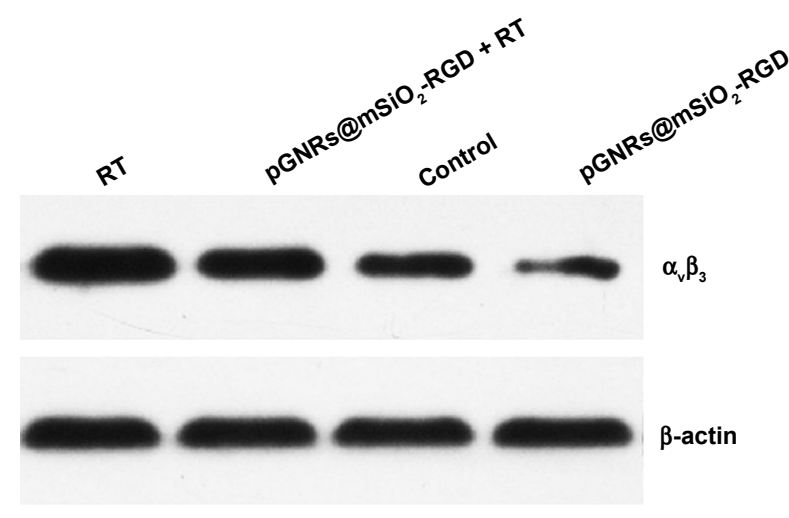

Figure 10 The effect of pGNRs@mSiO ${ }_{2}$-RGD nanoprobes on integrin $\alpha_{v} \beta_{3}$ expression as evidenced by Western blotting.

Notes: MDA-MB-23I cells were incubated with pGNRs@mSiO -RGD 24 hours prior to treatment with $6 \mathrm{MV} X$-rays $(6 \mathrm{~Gy})$. $\beta$-actin was used as the loading control. pGNRs@mSiO , mesoporous silica-encapsulated gold nanorods; pGNRs@mSiO RGD, RGD-conjugated mesoporous silica-encapsulated gold nanorods; integrin $\alpha_{v} \beta_{3}$, integrin alphaV beta3; RGD, arginine-glycine-aspartic acid (Arg-Gly-Asp) peptides. Abbreviation: RT, radiation.

nanoprobes was assessed (Figure 11). Twenty-four hours after the intravenous injection of nanoprobes, large amounts of pGNRs@mSiO_-RGD accumulated in the liver and spleen, which shows that these nanoprobes were mainly eliminated by the reticuloendothelial system. The targeted pGNRs@ $\mathrm{mSiO}_{2}$-RGD nanoprobes retained in the tumor at 24 hours was approximately three times higher than the nontargeted pGNRs@mSiO . Subsequently, we assessed tumor growth in vivo to RT in combination with the targeted nanoprobes.

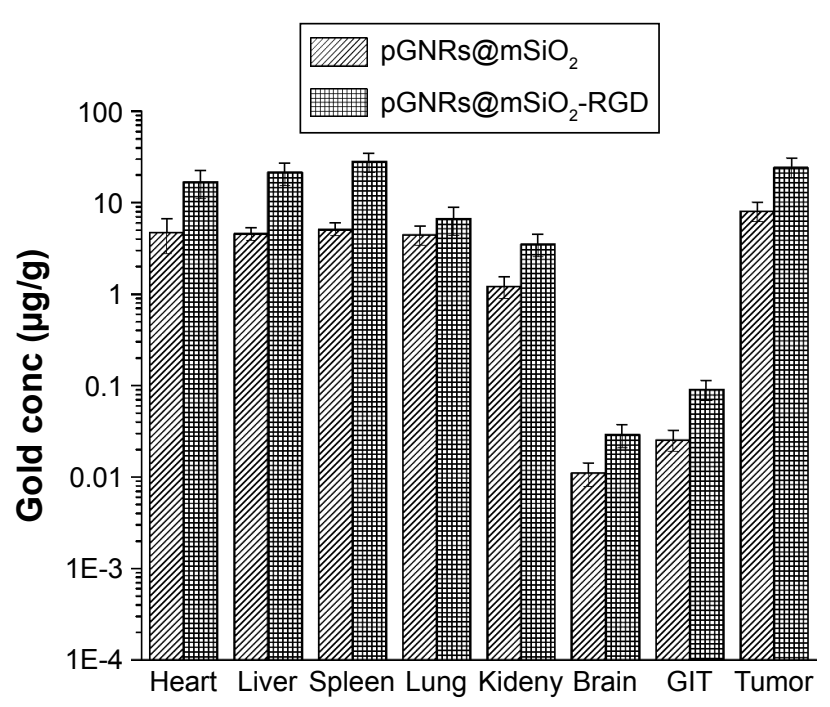

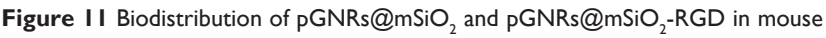
organs 24 hours after the intravenous injection of nanoparticles (I mg $\mathrm{Au}$ in $200 \mu \mathrm{L}$ of PBS).

Notes: Gold accumulation in tissue samples was evaluated by ICP-MS. pGNRs@ $\mathrm{mSiO}_{2}$, mesoporous silica-encapsulated gold nanorods; $\mathrm{PGNRs@mSiO}-\mathrm{RGD}$, RGD-conjugated mesoporous silica-encapsulated gold nanorods; RGD, arginineglycine-aspartic acid (Arg-Gly-Asp) peptides.

Abbreviations: ICP-MS, inductively coupled plasma mass spectrometry; GIT, gastrointestinal tract; PBS, phosphate-buffered saline; conc, concentration. 


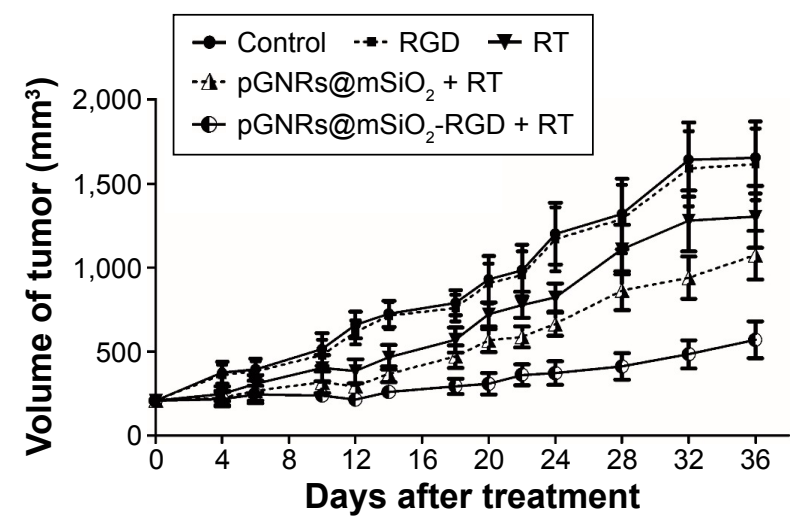

Figure 12 Tumor growth in nude mice bearing TNBC with or without treatment with pGNRs@mSiO or pGNRs@mSiO 2 -RGD nanoprobes 24 hours prior to irradiation with $6 \mathrm{MV}$ X-rays (10 Gy).

Notes: pGNRs@mSiO, mesoporous silica-encapsulated gold nanorods; pGNRs@ $\mathrm{mSiO}_{2}-\mathrm{RGD}, \mathrm{RGD}$-conjugated mesoporous silica-encapsulated gold nanorods; RGD, arginine-glycine-aspartic acid (Arg-Gly-Asp) peptides.

Abbreviations: TNBC, triple-negative breast cancer; RT, radiation.

\section{In vivo evaluation of the ability of multifunctional GNRs to delay tumor growth}

Tumor growth was significantly delayed in the orthotopic transplantation model treated with $\mathrm{pGNRs@mSiO}$ - $\mathrm{RGD}+\mathrm{RT}$ nanoprobes (Figure 12). After treatment for 1 month, we found that pGNRs@mSiO $2-\mathrm{RGD}+\mathrm{RT}$ markedly reduced tumor growth $\left(569 \pm 154 \mathrm{~mm}^{3}\right)$ compared with pGNRs@ $\mathrm{mSiO}_{2}+\mathrm{RT}$ $\left(1,073 \pm 205 \mathrm{~mm}^{3}\right)$ and RT alone $\left(1,302 \pm 261 \mathrm{~mm}^{3} ; P<0.05\right)$. There was no difference between the negative control (RGD alone, 1,656 $\pm 303 \mathrm{~mm}^{3}$ ) and the untreated control $\left(1,615 \pm 303 \mathrm{~mm}^{3} ; P>0.05\right)$; no radiosensitizing effects were detected in this negative control group.

\section{Characterizing the tumor uptake of pGNRs@mSiO 2 -RGD nanoprobes}

After the TNBC mouse models were treated with the pGNRs@ $\mathrm{mSiO}_{2}-\mathrm{RGD}$ nanoprobes, the tumor tissues were examined by TEM. Figure $\mathrm{S} 6$ shows the clustered distribution of pGNRs@mSiO - -RGD in the tumor cell cytoplasm.

\section{Discussion}

GNPs have been reported to enhance the effects of RT on tumor cells. ${ }^{7-9}$ Nanoparticles can be retained in tumors through two independent mechanisms: passive targeting and active targeting. Passive targeting is based on the preferential accumulation of nanoparticles within tumor tissue by permeating the leaky angiogenic endothelium (enhanced permeability and retention effect), but specific tumor targeting is not possible. Active targeting can increase the cellular internalization of nanoparticles and the ionization density within the cytoplasm, which significantly contributes to radiosensitization, especially for megavoltage $\mathrm{RT}$. A recent study showed that goserelin-conjugated GNRs significantly increased the radiosensitivity of prostate cancer to megavoltage energy. ${ }^{11}$ Therefore, we aimed to develop biocompatible and effective multifunctional nanoprobes for active tumortargeting therapy.

In the present study, we successfully developed a delivery system of pGNRs@mSiO 2 -RGD, which can be used for active tumor-targeting therapy. CTAB, an important structure-directing agent, played a key role in the synthesis of the GNRs. However, surfactant CTAB resulted in the severe cytotoxicity and poor biocompatibility of GNRs. Silica has been reported to be extremely biocompatible and easily surface-modifiable with functional groups; therefore, the CTAB-stabilized GNRs were coated with silica to eliminate the cytotoxicity. From the TEM imaging, we determined that the targeted GNRs formed clusters in the cytoplasm of MDA-MB-231 cells, which increases the interaction cross-section of RT within the cell and yields numerous secondary electrons. ${ }^{32,33}$

The clonogenic survival data demonstrated that the pGNRs@mSiO - RGD nanoprobes exerted a greater radiosensitizing effect in MDA-MB-231 cells than pGNRs@ $\mathrm{mSiO}_{2}$, indicating that multifunctional GNRs enhanced the sensitization of TNBC to megavoltage $\mathrm{X}$-rays in vitro. The mechanisms by which pGNRs@mSiO ${ }_{2}$-RGD produced a greater dose enhancement were correlated with several factors.

The concentration of the GNPs was previously demonstrated to be positively associated with an increase in radiosensitization. ${ }^{18}$ Our study showed that the cellular uptake of pGNRs@ $\mathrm{mSiO}_{2}$-RGD nanoprobes by MDA-MB-231 cells

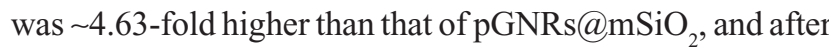
the surface receptor $\alpha_{v} \beta_{3}$ was blocked with free RGD, we found that the cellular internalization of pGNRs@ $\mathrm{mSiO}_{2}-$ RGD was markedly suppressed, demonstrating that RGD markedly increased the tumor-targeting ability of GNRs.

To the best of our knowledge, the radiosensitization of tumor cells is mainly related to apoptosis and the cell cycle. To obtain a better understanding of the mechanism underlying the dose enhancement effect of pGNRs@ $@ \mathrm{mSiO}_{2}$-RGD nanoprobes, we examined the cell cycle and apoptosis of MDAMB-231 cells after treatment with pGNRs@mSiO $-\mathrm{RGD}$. Our present study demonstrated that pGNRs@ $\mathrm{mSiO}_{2}-\mathrm{RGD}$ or irradiation alone could induce moderately radiosensitive $\mathrm{G}_{2} / \mathrm{M}$ cell cycle arrest, whereas the combination of these two treatments had the synergistic effect of increasing the population of cells in $\mathrm{G}_{2} / \mathrm{M}$. Tumor cells are more sensitive to 
RT in $\mathrm{G}_{2} / \mathrm{M}$ and are less sensitive in the $\mathrm{G}_{0} / \mathrm{G}_{1}$ or $\mathrm{S}$ phases $;^{34}$ thus, a combination of pGNRs@ $\mathrm{mSiO}_{2}$-RGD and irradiation could result in increased cellular RT damage. Studies have demonstrated that nanoparticles cause DNA damage and the $\mathrm{G}_{2} / \mathrm{M}$ arrest of tumor cells. It has been shown that treating the A549 lung cancer cell line with nanoparticles induced DNA damage and $\mathrm{G}_{2} / \mathrm{M}$ arrest, and the induction of $\mathrm{G}_{2} / \mathrm{M}$ arrest was determined by the activation of P53 and the increased phosphorylation of the P53-binding protein, BRCA1, and $\gamma \mathrm{H}_{2}$ AX proteins. ${ }^{35}$ Moreover, $\mathrm{G}_{2} / \mathrm{M}$ arrest was connected to a checkpoint kinase 1-associated signaling pathway, resulting in the inactivation of cyclin B1/Cdc2, and the nanoparticles could induce the phosphorylation of $\mathrm{Cdc} 2$ and $\mathrm{Cdc} 25 \mathrm{C}$ prior to mitosis and cause the inactivation of cyclin $\mathrm{B} 1 .^{36}$ Understanding the molecular mechanisms underlying the $\mathrm{G}_{2} / \mathrm{M}$ arrest caused by pGNRs@ $\mathrm{mSiO}_{2}$-RGD nanoprobes requires further investigation.

The apoptosis data indicated that the combined treatment of pGNRs@mSiO $-\mathrm{RGD}$ and irradiation had an additive effect of increasing the proportion of apoptotic cells. As previously reported, increasing the proportion of apoptotic cells can promote radiosensitivity. ${ }^{37}$ Thus, we thought that pGNRs@mSiO - RGD nanoprobes may promote the radiosensitization of MDA-MB-231 cells by the apoptosis mechanism.

Apoptosis is regulated by the expression of proapoptotic proteins (eg, Bax) and antiapoptotic proteins (eg, Bcl-2 and Bcl-xL). ${ }^{38}$ The irradiation-induced Bcl-2 downregulation and Bax upregulation are related to enhanced radiosensitization; thus, the ratio of Bcl-2/Bax plays a pivotal role in radiosensitization. ${ }^{39}$ Silver nanoparticles have been previously reported to interact with the cellular proteins that regulate apoptosis, thereby influencing their function. ${ }^{40}$ Thus, we speculated that pGNRs@ $\mathrm{mSiO}_{2}$-RGD nanoprobes may likewise enhance the radiosensitization of MDA-MB-231 cells by affecting the apoptosis regulatory pathways; further experiments will be conducted to confirm this hypothesis.

Generally, excessive ROS generation leads to intracellular protein modification and DNA damage, triggering cell death by regulating downstream signaling pathways. The intracellular ROS levels could play a key role in the apoptosis signal transduction pathway and promote MDA-MB-231 cell apoptosis, thereby increasing radiosensitization. ${ }^{41}$ Our findings showed that the intracellular ROS levels in the pGNRs@ $\mathrm{mSiO}_{2}-\mathrm{RGD}$ and $\mathrm{RT}$ cotreatment group were markedly higher than those in the other groups, suggesting that the pGNRs@ $\mathrm{mSiO}_{2}-\mathrm{RGD}$ nanoprobes may enhance radiosensitization by increasing ROS production. It has been reported that excessive ROS production leads to oxidative damage and acts on Bcl-2 family proteins that regulate apoptosis. ${ }^{42}$ Therefore, the question of whether pGNRs@ $\mathrm{mSiO}_{2}-\mathrm{RGD}$ nanoprobes target specific intracellular proteins and the underlying molecular mechanisms deserves further investigation.

Additionally, the percentage of MDA-MB-231 cells in $\mathrm{G}_{2} / \mathrm{M}$, the apoptosis rates, and the intracellular ROS levels induced by cotreatment with pGNRs@mSiO 2 -RGD and RT were markedly higher than those observed after treatment with pGNRs@mSiO_plus RT.We speculated that these results may be attributed to the superior intracellular uptake of the pGNRs@mSiO with pGNRs@mSiO .

Inhibition of integrin $\alpha_{\mathrm{v}} \beta_{3}$ expression might also explain the radiosensitizing effect of RGD-GNRs. The integrin $\alpha_{\mathrm{v}} \beta_{3}$ receptor is expressed on some tumor cells and tumor vascular endothelial cells, where it plays a crucial role in tumor growth, angiogenesis, and invasion. Soluble cRGD peptides, integrin $\alpha_{v} \beta_{3}$ receptor-specific ligands, have been reported to block the adhesion, invasion, and metastasis of breast cancer cells. ${ }^{43,44}$ GNRs serve as cRGD peptide carriers that not only promote specific binding to tumor cells but also increase the absorption of RT energy and the preferential accumulation in tumor tissues. ${ }^{12}$ Our findings showed that pGNRs@ $\mathrm{mSiO}_{2}-\mathrm{RGD}$ nanoprobes could downregulate the expression of integrin $\alpha_{\mathrm{v}} \beta_{3}$ induced by RT and under control conditions, presumably leading to the dose enhancement effect. Integrin $\alpha_{v} \beta_{3}$ transmits signals by activating the ERK1/ERK2 MAPK and PI-3K/AKT pathways. ${ }^{45}$ Meyer et $\mathrm{l}^{46}$ performed fluorocytometry and found that the classical vitronectin receptor $\alpha_{v} \beta_{3}$ is expressed in only one of the eight breast cancer cell lines examined, namely MDA-MB-231 cell line. Menendez et $\mathrm{al}^{47}$ showed that the basal level of $\alpha_{\mathrm{v}} \beta_{3}$ expression was significantly higher in MDA-MB-231 cells, which also overexpressed both HRG and CYR61. Vellon et $\mathrm{al}^{48}$ found that heregulin was closely related to breast cancer progression and metastasis, regulated $\alpha_{\mathrm{v}} \beta_{3}$ levels and $\alpha_{\mathrm{v}} \beta_{3}$-triggered signaling through its downstream effector, CYR61, in MDA-MB-231 cells. CYR61 overexpression induced the activation of the Raf-MEK1/MEK2-ERK1/ERK2 cascade, which might promote breast cancer cell proliferation, growth, and survival. ${ }^{47}$ Besides, RT could upregulate the expression of $\alpha_{\mathrm{v}} \beta_{3}$ and activate the key antiapoptic protein kinase, Akt, and thus defend against RT damage. ${ }^{22}$ Therefore, we speculated that targeting $\alpha_{v} \beta_{3}$ might simultaneously prevent breast cancer angiogenesis, growth, and radioresistance and inhibition of integrin $\alpha_{\mathrm{v}} \beta_{3}$ survival signaling by RGD-GNRs might lead to the enhancing radiosensitization of tumor cell. 
To realize the translation of nanotechnology to clinical trials, it is essential to assess the efficacy of multifunctional pGNRs@ $\mathrm{mSiO}_{2}$-RGD nanoprobes in vivo. The biodistribution data indicated that the pGNRs@mSiO $-\mathrm{RGD}$ were better retained within the tumor tissues than pGNRs@ $\mathrm{mSiO}_{2}$, their intratumoral concentration was three times greater than that of pGNRs@ $\mathrm{mSiO}_{2}$ after systemic administration of GNPs. The increasing GNPs concentration in the tumor tissues will be positively related to the radiosensitization enhancement. Accumulation of GNPs inside the cells could enhance the radiosensitivity as potential photon and electron interaction increase and studies suggested that localization of GNPs within the cells is an important factor in increasing the RT cytotoxicity. ${ }^{49}$ We also found that pGNRs@mSiO - RGD nanoprobes in combination with megavoltage RT delayed tumor growth in nude mice harboring TNBC. Thus, these results suggest that the multifunctional pGNRs@mSiO RGD nanoprobes evoke a significant radiosensitization to megavolt RT.

\section{Conclusion}

The present study provided substantial evidence that pGNRs@mSiO - RGD could be internalized by MDA-MB231 TNBC cells by targeting tumor-specific antigens, leading to radiosensitization in combination with megavoltage RT in vitro and in vivo. This study provides a foundation for further investigations of the sensitization effects of anticancer drug-loaded GNRs@mSiO megavoltage RT. Moreover, the specific mechanisms of radiosensitivity caused by the multifunctional GNRs require further exploration at the molecular level.

\section{Acknowledgment}

This work was financially supported by a research grant (YG2012ZD02, 2JC1407400) from Shanghai Jiao Tong University and the Science and Technology Commission of Shanghai, People's Republic of China, and a grant $(81272506,61227017)$ from the National Natural Science Foundation of China.

\section{Disclosure}

The authors report no conflicts of interest in this work.

\section{References}

1. Chow EK, Ho D. Cancer nanomedicine: from drug delivery to imaging. Sci Transl Med. 2013;5(216):216rv4.

2. Bhattacharyya S, Kudgus RA, Bhattacharya R, Mukherjee P. Inorganic nanoparticles in cancer therapy. Pharm Res. 2011;28(2):237-259.

3. Huang X, El-Sayed IH, Qian W, El-Sayed MA. Cancer cell imaging and photothermal therapy in the near-infrared region by using gold nanorods. J Am Chem Soc. 2006;128(6):2115-2120.
4. von Maltzahn G, Centrone A, Park JH, et al. SERS-Coded gold nanorods as a multifunctional platform for densely multiplexed near-infrared imaging and photothermal heating. Adv Mater. 2009;21(31):3175-3180.

5. Liu CJ, Wang CH, Chen ST, et al. Enhancement of cell radiation sensitivity by pegylated gold nanoparticles. Phys Med Biol. 2010;55(4): 931-945.

6. Sancey L, Barbier E, Hirsjarvi S, et al. Enhanced permeability and retention (EPR) effect in tumors: characterization by MRI and fluorescence imaging. Bull Cancer. 2011;98(suppl):S67.

7. Yasui H, Takeuchi R, Nagane M, et al. Radiosensitization of tumor cells through endoplasmic reticulum stress induced by PEGylated nanogel containing gold nanoparticles. Cancer Lett. 2014;347(1):151-158.

8. Khoshgard K, Hashemi B, Arbabi A, Rasaee MJ, Soleimani M. Radiosensitization effect of folate-conjugated gold nanoparticles on HeLa cancer cells under orthovoltage superficial radiotherapy techniques. Phys Med Biol. 2014;59(9):2249-2263.

9. Geng F, Xing JZ, Chen J, et al. Pegylated glucose gold nanoparticles for improved in-vivo bio-distribution and enhanced radiotherapy on cervical cancer. J Biomed Nanotechnol. 2014;10(7):1205-1216.

10. Jain S, Coulter JA, Hounsell AR, et al. Cell-specific radiosensitization by gold nanoparticles at megavoltage radiation energies. Int $J$ Radiat Oncol Biol Phys. 2011;79(2):531-539.

11. Wolfe T, Chatterjee D, Lee J, et al. Targeted gold nanoparticles enhance sensitization of prostate tumors to megavoltage radiation therapy in vivo. Nanomedicine. 2015;11(5):1277-1283.

12. Zheng Y, Hunting DJ, Ayotte P, Sanche L. Radiosensitization of DNA by gold nanoparticles irradiated with high-energy electrons. Radiat Res. 2008;169(1):19-27.

13. Mayer IA, Abramson VG, Lehmann BD, Pietenpol JA. New strategies for triple-negative breast cancer - deciphering the heterogeneity. Clin Cancer Res. 2014;20(4):782-790.

14. Zaky SS, Lund M, May KA, et al. The negative effect of triple-negative breast cancer on outcome after breast-conserving therapy. Ann Surg Oncol. 2011;18(10):2858-2865.

15. Fornier M, Fumoleau P. The paradox of triple negative breast cancer: novel approaches to treatment. Breast J. 2012;18(1):41-51.

16. Bauer KR, Brown M, Cress RD, Parise CA, Caggiano V. Descriptive analysis of estrogen receptor (ER)-negative, progesterone receptor (PR)-negative, and HER2-negative invasive breast cancer, the so-called triple-negative phenotype: a population-based study from the California cancer registry. Cancer. 2007;109(9):1721-1728.

17. Ren YQ, Fu F, Han J. MiR-27a modulates radiosensitivity of triple-negative breast cancer (TNBC) cells by targeting CDC27. Med Sci Monit. 2015;21:1297-1303.

18. Rahman WN, Bishara N, Ackerly T, et al. Enhancement of radiation effects by gold nanoparticles for superficial radiation therapy. Nanomedicine. 2009;5(2):136-142.

19. Monferran S, Skuli N, Delmas C, et al. Alphavbeta3 and alphavbeta5 integrins control glioma cell response to ionising radiation through ILK and RhoB. Int J Cancer. 2008;123(2):357-364.

20. Pierschbacher MD, Ruoslahti E. Cell attachment activity of fibronectin can be duplicated by small synthetic fragments of the molecule. Nature. 1984;309(5963):30-33.

21. Lautenschlaeger T, Perry J, Peereboom D, et al. In vitro study of combined cilengitide and radiation treatment in breast cancer cell lines. Radiat Oncol. 2013;8:246.

22. Abdollahi A, Griggs DW, Zieher H, et al. Inhibition of alpha(v)beta3 integrin survival signaling enhances antiangiogenic and antitumor effects of radiotherapy. Clin Cancer Res. 2005;11(17):6270-6279.

23. Albert JM, Cao C, Geng L, Leavitt L, Hallahan DE, Lu B. Integrin alpha $v$ beta 3 antagonist Cilengitide enhances efficacy of radiotherapy in endothelial cell and non-small-cell lung cancer models. Int J Radiat Oncol Biol Phys. 2006;65(5):1536-1543.

24. Yang DP, Cui DX. Advances and prospects of gold nanorods. Chem Asian J. 2008;3(12):2010-2022.

25. Su N, Dang Y, Liang G, Liu G. Iodine-125-labeled cRGD-gold nanoparticles as tumor-targeted radiosensitizer and imaging agent. Nanoscale Res Lett. 2015;10:160. 
26. Vilchis-Juárez A, Ferro-Flores G, Santos-Cuevas C, et al. Molecular targeting radiotherapy with cyclo-RGDFK(C) peptides conjugated to 177Lu-labeled gold nanoparticles in tumor-bearing mice. J Biomed Nanotechnol. 2014;10(3):393-404.

27. Li P, Shi YW, Li BX, et al. Photo-thermal effect enhances the efficiency of radiotherapy using Arg-Gly-Asp peptides-conjugated gold nanorods that target $\alpha \mathrm{v} \beta 3$ in melanoma cancer cells. J Nanobiotechnology. 2015;13(1):52.

28. $\mathrm{Xu} \mathrm{W}$, Luo T, Li P, et al. RGD-conjugated gold nanorods induce radiosensitization in melanoma cancer cells by downregulating $\alpha(\mathrm{v})$ $\beta_{3}$ expression. Int J Nanomedicine. 2012;7:915-924.

29. Karakoti AS, Das S, Thevuthasan S, Seal S. PEGylated inorganic nanoparticles. Angew Chem Int Ed Engl. 2011;50(9):1980-1994.

30. Wang CG, Ma ZF, Wang TT, Su ZM. Synthesis, assembly, and biofunctionalization of silica-coated gold nanorods for colorimetric biosensing. Adv Funct Mater. 2006;16(13):1673-1678.

31. Liz-Marzan LM, Giersig M, Mulvaney P. Synthesis of nanosized goldsilica core-shell particles. Langmuir. 1996;12(18):4329-4335.

32. Amato E, Italiano A, Pergolizzi S. Gold nanoparticles as a sensitising agent in external beam radiotherapy and brachytherapy: a feasibility study through Monte Carlo simulation. Int J Nanotechnol. 2013;10(12): 1045-1054.

33. Butterworth KT, McMahon SJ, Currell FJ, Prise KM. Physical basis and biological mechanisms of gold nanoparticle radiosensitization. Nanoscale. 2012;4(16):4830-4838.

34. Sinclair WK. Cyclic $\mathrm{x}$-ray responses in mammalian cells in vitro. Radiat Res. 1968;33(3):620-643.

35. Mroz RM, Schins RP, Li H, et al. Nanoparticle-driven DNA damage mimics irradiation-related carcinogenesis pathways. Eur Respir J. 2008; 31(2):241-251.

36. Rahman HS, Rasedee A, Abdul AB, et al. Zerumbone-loaded nanostructured lipid carrier induces G2/M cell cycle arrest and apoptosis via mitochondrial pathway in a human lymphoblastic leukemia cell line. Int J Nanomedicine. 2014;9:527-538.

37. Meyn RE, Stephens LC, Ang KK, et al. Heterogeneity in the development of apoptosis in irradiated murine tumours of different histologies. Int $J$ Radiat Biol. 1993;64(5):583-591.

38. Wood WG, Igbavboa U, Muller WE, Eckert GP. Statins, Bcl-2, and apoptosis: cell death or cell protection? Mol Neurobiol. 2013;48(2):308-314.
39. Hara T, Omura-Minamisawa M, Chao C, Nakagami Y, Ito M, Inoue T. $\mathrm{Bcl}-2$ inhibitors potentiate the cytotoxic effects of radiation in Bcl-2 overexpressing radioresistant tumor cells. Int J Radiat Oncol Biol Phys. 2005;61(2):517-528.

40. Asharani P, Sethu S, Lim HK, Balaji G, Valiyaveettil S, Hande MP. Differential regulation of intracellular factors mediating cell cycle, DNA repair and inflammation following exposure to silver nanoparticles in human cells. Genome Integr. 2012;3(1):2.

41. Yao JX, Yao ZF, Li ZF, Liu YB. Radio-sensitization by Piper longumine of human breast adenoma MDA-MB-231 cells in vitro. Asian Pac J Cancer Prev. 2014;15(7):3211-3217.

42. Meng FM, Yang JB, Yang $\mathrm{CH}$, et al. Vitexicarpin induces apoptosis in human prostate carcinoma PC-3 cells through G2/M phase arrest. Asian Pac J Cancer Prev. 2012;13(12):6369-6374.

43. Georgoulis A, Havaki S, Drosos Y, et al. RGD binding to integrin alphavbeta3 affects cell motility and adhesion in primary human breast cancer cultures. Ultrastruct Pathol. 2012;36(6):387-399.

44. Li S, Wei J, Yuan L, et al. RGD-modified endostatin peptide 30 derived from endostatin suppresses invasion and migration of HepG2 cells through the $\alpha v \beta 3$ pathway. Cancer Biother Radiopharm. 2011;26(5): 529-538.

45. Stupack DG, Cheresh DA. Get a ligand, get a life: integrins, signaling and cell survival. J Cell Sci. 2002;115(pt 19):3729-3738.

46. Meyer T, Marshall JF, Hart IR. Expression of alphav integrins and vitronectin receptor identity in breast cancer cells. Br J Cancer. 1998;77(4): 530-536.

47. Menendez JA, Vellon L, Mehmi I, Teng PK, Griggs DW, Lupu R. A novel CYR61-triggered 'CYR61-alphavbeta3 integrin loop' regulates breast cancer cell survival and chemosensitivity through activation of ERK1/ERK2 MAPK signaling pathway. Oncogene. 2005;24(5): 761-779.

48. Vellon L, Menendez JA, Lupu R. AlphaVbeta3 integrin regulates heregulin (HRG)-induced cell proliferation and survival in breast cancer. Oncogene. 2005;24(23):3759-3773.

49. Babaei M, Ganjalikhani M. The potential effectiveness of nanoparticles as radio sensitizers for radiotherapy. Bioimpacts. 2014;4(1):15-20. 


\section{Supplementary materials}
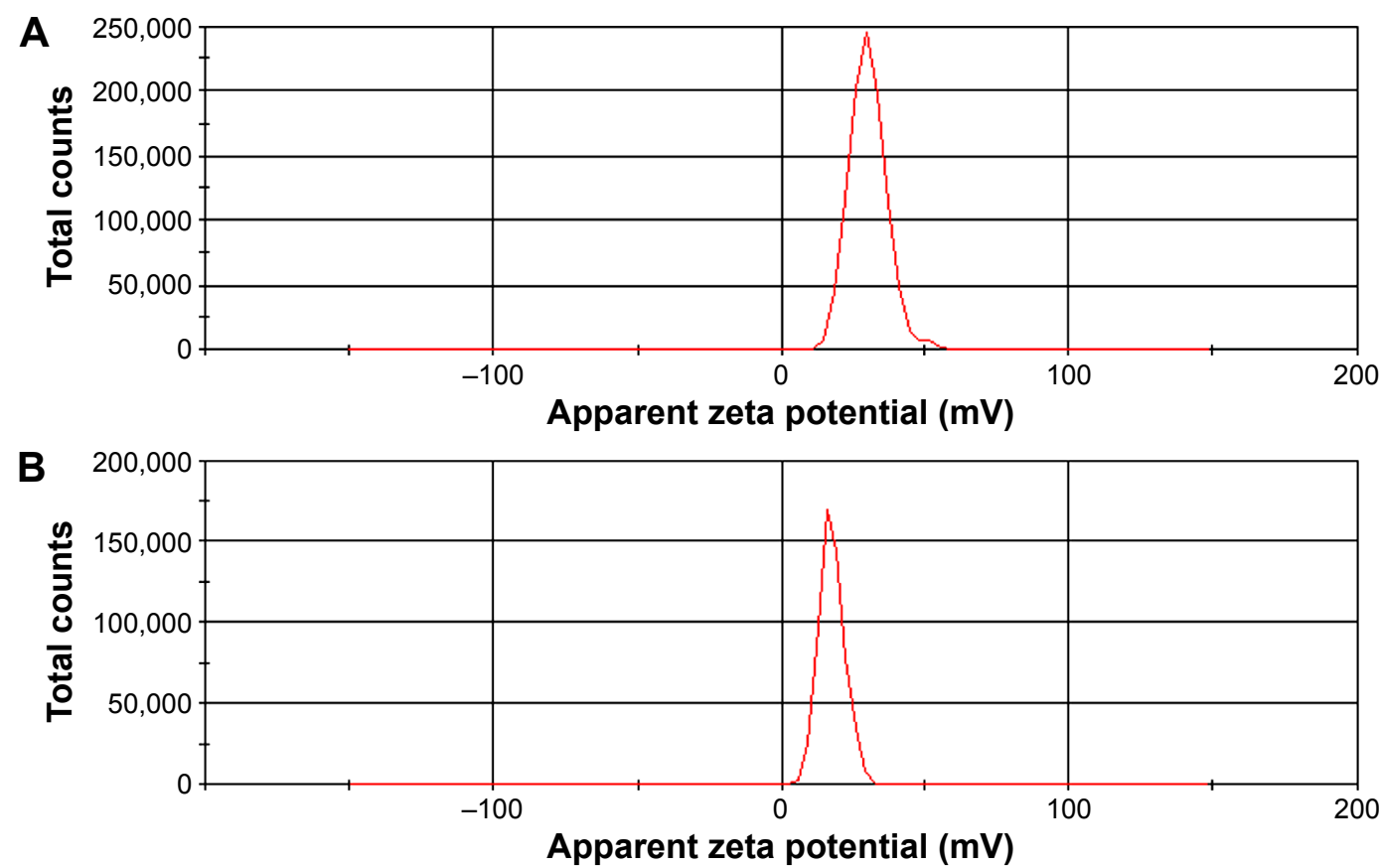

Figure SI Zeta potential distribution.

Notes: (A) The zeta potential of the GNRs@mSiO $-\mathrm{NH}_{2}$ nanoparticles was $35.1 \pm 7.01 \mathrm{mV}$; (B) the zeta potential of the pGNRs@mSiO $-\mathrm{RGD}$ nanoprobes was I7.5 $\pm 4.37 \mathrm{mV}$. GNRs@mSiO $-\mathrm{NH}_{2}$, mesoporous silica-encapsulated gold nanorods conjugated with $\mathrm{NH}_{2}$ groups; pGNRs@mSiO - -RGD, RGD-conjugated mesoporous silica-encapsulated gold nanorods; RGD, arginine-glycine-aspartic acid (Arg-Gly-Asp, RGD) peptides.

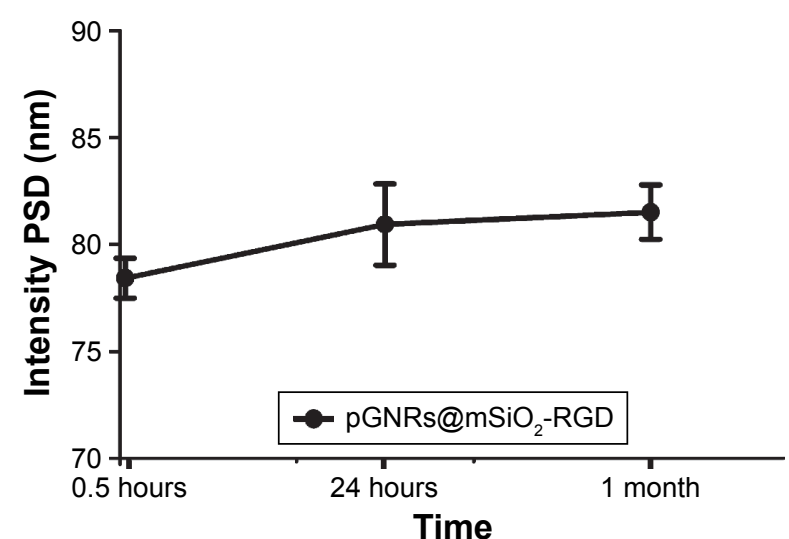

Figure S2 Hydrodynamic diameters of pGNRs@mSiO $-R G D$ nanoprobes at different periods of time ( 0.5 hours, 24 hours, and I month), they were $78.43 \pm I .32$ nm, $80.94 \pm 2.69 \mathrm{~nm}$, and $81.52 \pm 1.80 \mathrm{~nm}$, respectively.

Notes: pGNRs@mSiO 2 -RGD, RGD-conjugated mesoporous silica-encapsulated gold nanorods; RGD, arginine-glycine-aspartic acid (Arg-Gly-Asp, RGD) peptides; PSD, particle size distribution. 

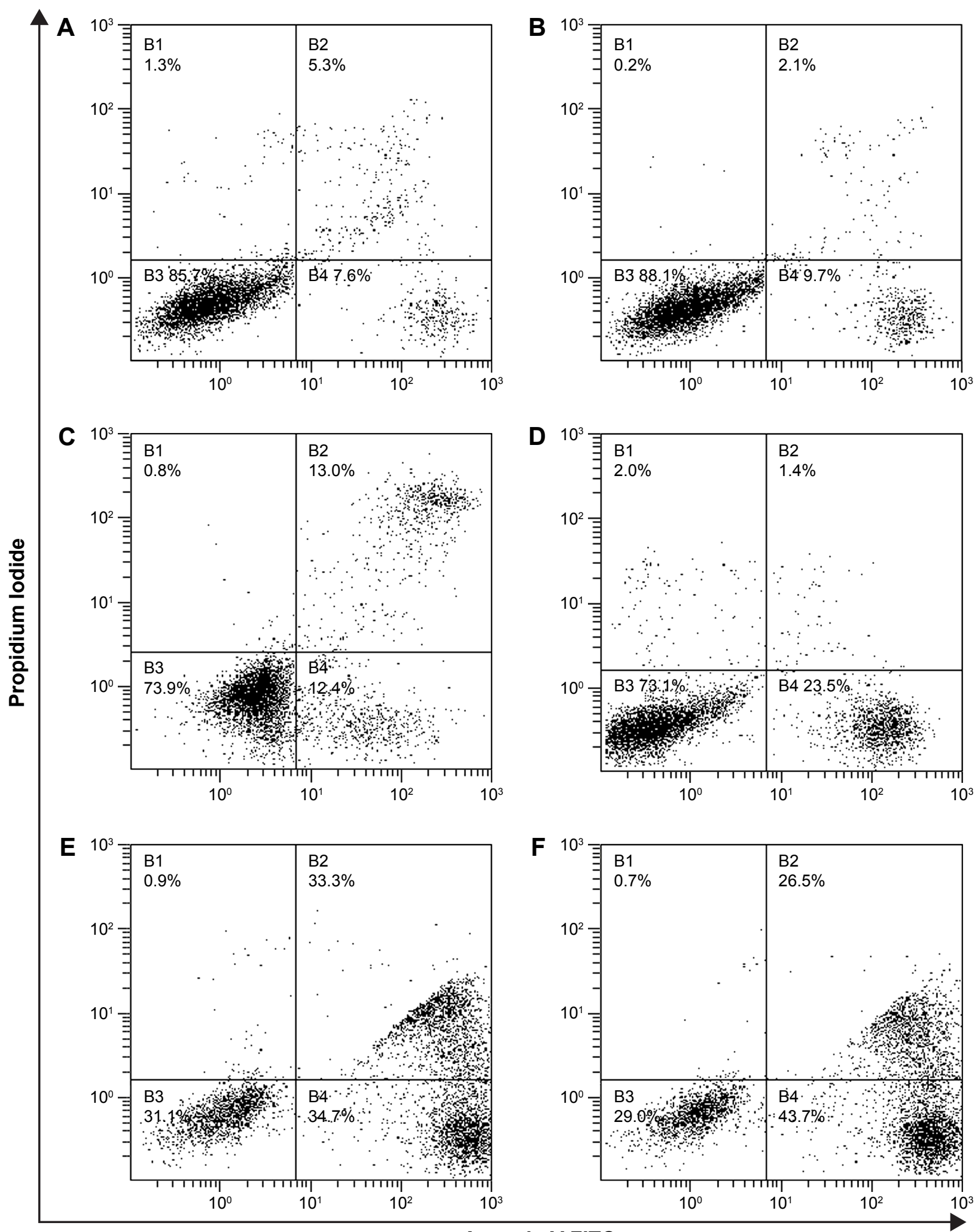

Annexin V FITC

Figure S3 Flow cytometry analysis of MDA-MB-23I cell apoptosis.

Notes: (A-F) Apoptosis of MDA-MB-23I cells exposed to pGNRs@mSiO or pGNRs@mSiO $-R G D$ nanoprobes for 24 hours with or without 6 MV X-rays (6 Gy). (A) Control, (B) pGNRs@mSiO, , (C) pGNRs@mSiO $-R G D$, (D) RT, (E) pGNRs@mSiO 2 + RT, and (F) pGNRs@mSiO $2-R G D+R T$. pGNRs@mSiO ${ }_{2}$, mesoporous silicaencapsulated gold nanorods; pGNRs@mSiO 2 -RGD, RGD-conjugated mesoporous silica-encapsulated gold nanorods; RGD, arginine-glycine-aspartic acid (Arg-Gly-Asp) peptides. Variables BI-B4 respectively refer to necrotic cells, early stage apoptotic cells, normal cells, and late stage apoptotic cells. Abbreviation: RT, radiation. 

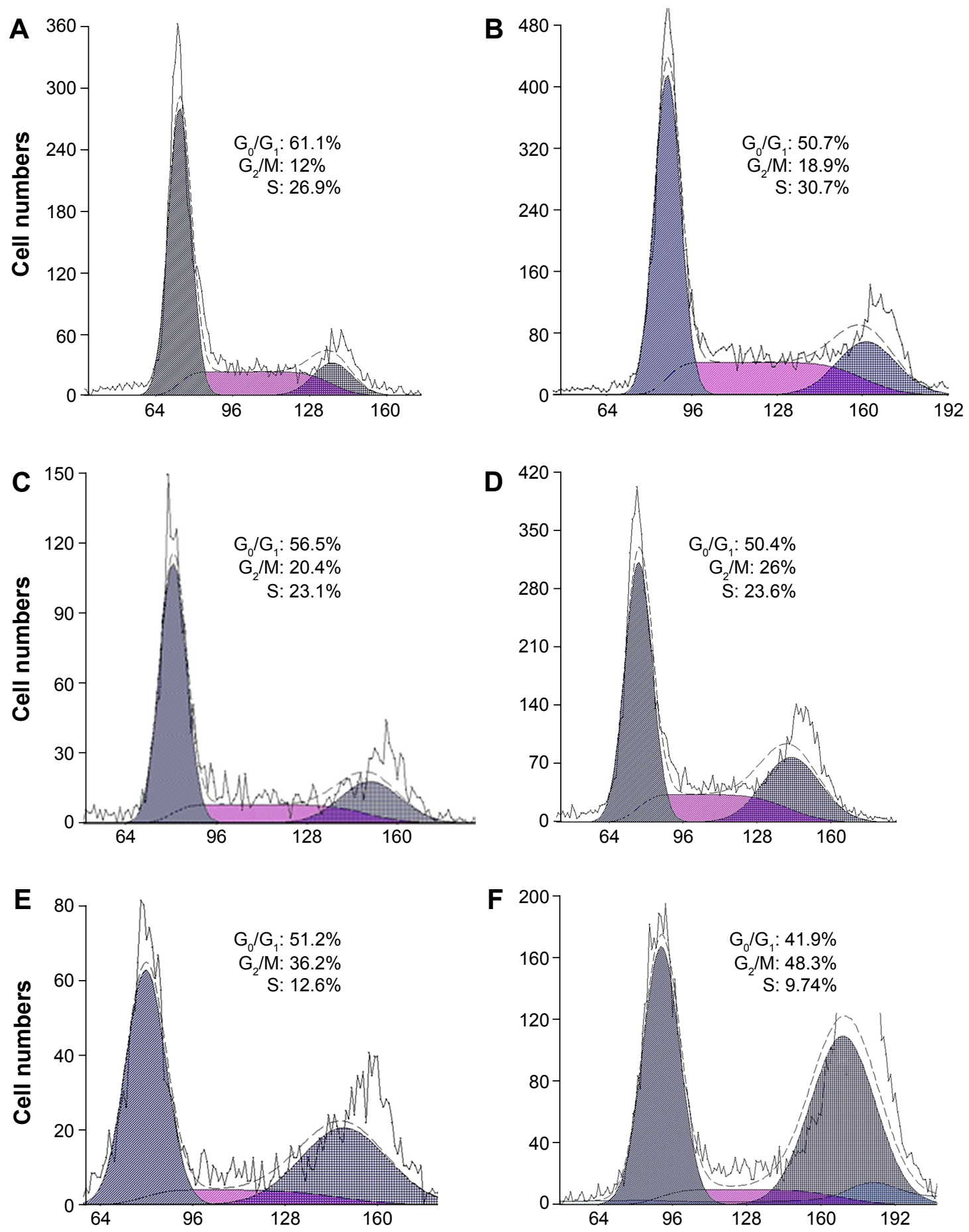

DNA contents

Figure $\mathbf{S} 4$ Flow cytometry analysis of $\mathrm{G}_{2} / \mathrm{M}$ cell cycle arrest in MDA-MB-23I cells.

Notes: (A-F) Percentage of MDA-MB-23I cells in $\mathrm{G}_{2} / \mathrm{M}$ after exposure to $\mathrm{pGNRs@mSiO}$, or pGNRs@mSiO $-\mathrm{RGD}$ nanoprobes for 24 hours with or without 6 MV X-rays

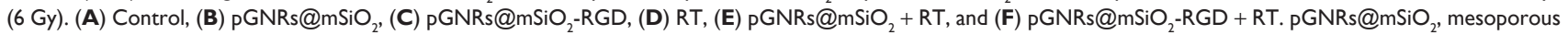
silica-encapsulated gold nanorods; pGNRs@mSiO $-R G D, R G D$-conjugated mesoporous silica-encapsulated gold nanorods; RGD, arginine-glycine-aspartic acid (Arg-GlyAsp) peptides. $G_{0} / G_{1}, G_{2} / M$, and $S$ are cell phases.

Abbreviation: $\mathrm{RT}$, radiation. 


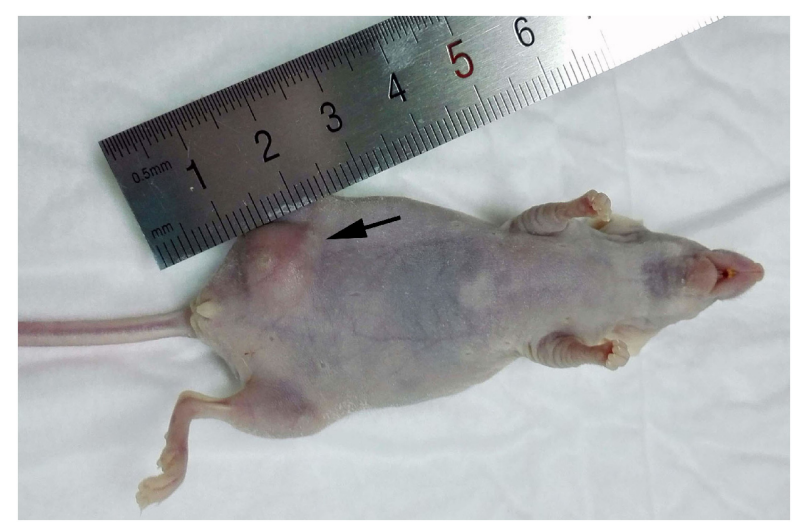

Figure S5 Orthotopic nude mouse model of TNBC (arrow).

Abbreviation: TNBC, triple-negative breast cancer.

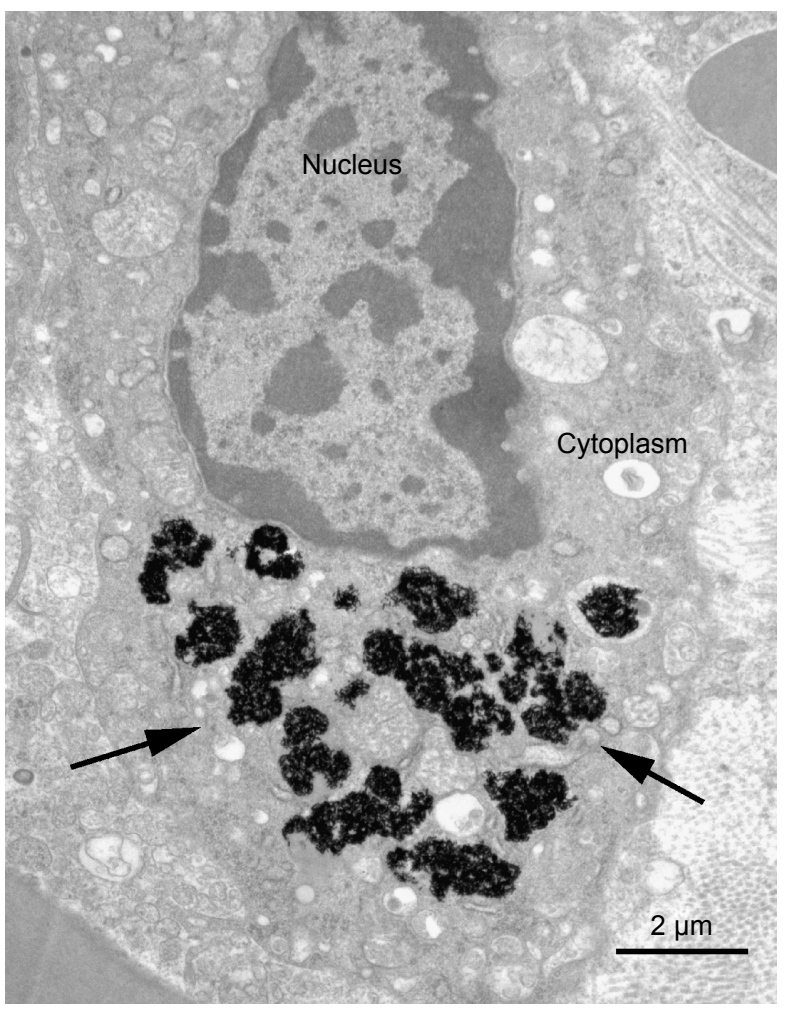

Figure S6 TNBC tumor tissues treated with pGNRs@mSiO $-\mathrm{RGD}+\mathrm{RT}$ (10 Gy).

Notes: The pGNRs@mSiO 2 -RGD (arrows) were clustered in the tumor cell cytoplasm. Scale bar=2 $\mu \mathrm{m}, 9,700 x$. pGNRs@mSiO 2 -RGD, RGD-conjugated mesoporous silica-encapsulated gold nanorods; RGD, arginine-glycine-aspartic acid (Arg-Gly-Asp) peptides.

Abbreviations: TNBC, triple-negative breast cancer; RT, radiation.

International Journal of Nanomedicine

\section{Publish your work in this journal}

The International Journal of Nanomedicine is an international, peerreviewed journal focusing on the application of nanotechnology in diagnostics, therapeutics, and drug delivery systems throughout the biomedical field. This journal is indexed on PubMed Central, MedLine, CAS, SciSearch ${ }^{\circledR}$, Current Contents ${ }^{\circledR} /$ Clinical Medicine,

\section{Dovepress}

Journal Citation Reports/Science Edition, EMBase, Scopus and the Elsevier Bibliographic databases. The manuscript management system is completely online and includes a very quick and fair peer-review system, which is all easy to use. Visit http://www.dovepress.com/ testimonials.php to read real quotes from published authors. 